\title{
COMPONENT FRAGILITY FOR USE IN PSA OF NUCLEAR POWER PLANT
}

\author{
Prabir C Basu ${ }^{1}$, M. K. Ravindra ${ }^{2}$, Yoshinori Mihara ${ }^{3}$ \\ ${ }^{1}$ Consultant, (Former Director (C\&SED), Atomic Energy Regulatory Board; \& Consultant, \\ ISSC, IAEA), India; \\ ${ }^{2}$ President, MK Ravindra Consulting, Irvine, California, USA; \\ ${ }^{3}$ Deputy Senior Manager, Nuclear Power Department, Kajima Corporation, Tokyo, Japan;
}

\begin{abstract}
The accident of Fukushima Nuclear Power Plant (NPP) underlines the necessity of conducting probabilistic safety assessment (PSA) of an NPP against the hazards caused by external events of natural origin and their combinations. One of the important tasks of an external event PSA (EE-PSA) of an NPP is determination of component fragility. The fragility is the probability of its reaching a limit state condition on a particular level of demand caused by the hazard. Fragility is expressed in terms of the median capacity $D_{m}$, random variability $\beta_{R}$ and uncertainty $\beta_{U}$ in the median capacity. $D_{m}$ is defined as median ground acceleration capacity $A_{m}$, wind velocity capacity $V_{m}$ and water height capacity $H_{m}$ for seismic, wind and flood (inundation) hazard respectively. For seismic fragility, there are direct and indirect methods to calculate fragility parameters $A_{m}, \beta_{R}$ and $\beta_{U}$. Direct method involves either analysis or testing. Indirect method is experience based method that maximizes the use of past experience in conjunction with plant walk down. The parameters for wind fragility $V_{m}, \beta_{R}$ and $\beta_{U}$ are estimated for different SSCs using design data (e. g. wall thickness, reinforcement, and anchorage) and variability associated with the wind response and capacity. Flood fragility is derived from flood response (e.g. inundation depth) and capacity (e.g. installation height). However, it generally shows more cliff-edge shape without any special barriers (e.g. protective walls, water-tight doors and sealing countermeasures). It means that flood fragility is highly path-dependent and thus flood hazard is influenced by barriers' fragility. The paper reviews the available open literature and summarizes the development of methods for deriving $D_{m}, \beta_{R}$ and $\beta_{U}$ of NPP components for use in PSA against seismic ground motion, wind and flood hazard. The paper also briefly discussed the external event PSA of multiple NPP units in a site for natural hazards like earthquake, wind and flood.
\end{abstract}

\section{INTRODUCTION}

In recent years, safety of nuclear power plants (NPP) has been challenged by external events like earthquake, high wind and flood. This highlights the necessity for probabilistic safety assessment (PSA) of an NPP against the hazards caused by external events of natural origin and their combinations. Three steps of external event PSA (EE-PSA) are,

(i) Hazard analysis,

(ii) Component fragility evaluation, and

(iii) Plant response analysis including quantification. 
ASME/ANS Probabilistic Risk Analysis (PRA) Standard [ASME/ANS (2011)] specifies the technical requirements for performing the above analyses. Terminologies PRA and PSA are interchangeable.

Among different external natural hazard, seismic hazard drew maximum attention of NPP safety analysts. All NPPs are to be designed for a minimum level of earthquake [IAEA (2010)]. Although USNRC published the guide for seismic PSA in 1983 [USNRC (1983)], actual work of seismic PSA of NPP started a few years before. A large number NPP had undergone Seismic PSA all over the world till date. The seismic PSA work is being continued covering more and more NPPs and for further improvement in methodologies. With regards to high (extreme) wind, it should be pointed out that till recently most US nuclear power plants had screened out this hazard from PSA. The basic reasoning was that the US nuclear power plants have been designed for the extreme loading and missiles from the design basis tornado. Similar situation exists in other parts of the world. In the last 5 years, there has been very detailed high wind PSA of a few nuclear power plants in the US. The qualitative and quantitative insights from these studies indicate that high wind risks are plant specific and care should be exercised in screening out the high wind hazards at any site. In case of flood hazard, major floods that may endanger safety of an NPP are caused by heavy precipitation and tsunami. EE-PSA against flood hazard or Flood-PSA of NPP is not very common. The flooding incident of Kakrapar Atomic Power Station (KAPS), India in 1994; flooding incident in French NPP Le-Blayasis in 1999; and Fukshima NPP accident in 2011 underline the importance of conducting Flood-PSA of NPP. Work has been started in different countries on safety assessment of NPP against flood. IAEA has taken up the extra budgetary project on development of flood PSA procedure.

Hazard is characterized and quantified in terms of hazard function (or curves) suitable to EEPSA in the first step. Seismic hazards could be quantified in terms of hazard curves for ground motion acceleration, ground velocity and ground displacement. However, for seismic PSA of NPP, the hazard customarily quantified in terms of ground acceleration. The extreme winds to be considered are tornado, hurricane (typhoon) and thunderstorm; depending on the location of the nuclear power plant, one or more of these types will affect the site. The IAEA Safety Report 'Assessment of External Flooding (Excluding Tsunami) and High Wind Hazards in Site Evaluation for Nuclear Installations' [IAEA (2015)] describes the methodologies for performing the wind hazard analysis. The outputs of the wind hazard analysis are hazard curves for wind speed (median, mean and fractiles or discrete family of curves). Missiles generated by tornadoes and hurricanes have the potential to damage SSCs of nuclear power plants. Missile risk analysis which combines the hazard and fragility aspects is also described in SRS-8.3 [IAEA (2015)]. Principal hazard of flood is inundation due to rise in water level at the site. The rise in water level also induces static water pressure and dynamic one as well. In addition drifting of debris, scouring are other flooding hazards. .

The second step of EE-PSA evaluates the component fragility. Fragility of a structure, system or component (SSC) of an NPP is the probability of its reaching a limit state conditioned on a particular value of a demand parameter [USNRC (1983)]. The limit state of the SSC could be limit state of strength leading to structural failure or limit state of serviceability leading to functional failure.

Probability of failure $P_{F}^{\prime}$ of a component having capacity $C$ at a given demand $D \leq d$ is:

$$
P_{F}^{\prime}=P_{f}(C \leq D \mid D \leq d) P(D \leq d)
$$


Where, $P_{f}(C \leq D \mid D \leq d)$ is the conditional probability that capacity is exceeded at demand $d$, i.e. reaching its limit state condition at demand $d . P(D \leq d)$ is the probability of occurrence of demand $d$. If $P(D \leq d)$ defines the hazard and assuming that the hazard is a continuous function of demand $d$, equation (1) takes following form,

$P_{F}^{\prime}=\int_{-\infty}^{d} P_{f}(d) z_{D}(d) \mathrm{d} d$

The conditional probability $P_{f}(d)$ is the fragility function. $z_{D}(d)$ represents hazard as demand.

Component fragility can be modelled using lognormal distribution, or Weibull distribution, or normal distribution [EPRI (1994)]. However, lognormal distribution is commonly used because of convenience due to some particular properties of this distribution. Using lognormal distribution, the component fragility is expressed as follows

$P_{f}(d)=P_{f}(D \leq d)=\varnothing\left[\frac{\ln (d)-\ln \left(D_{m}\right)}{\beta_{C}}\right]$

$\varnothing[\cdot]$ is the standard Gaussian cumulative distribution function, $D_{m}$ is the logarithmic median capacity and $\beta_{C}$ is the logarithmic standard deviation of the median capacity. The equation (3) calculates probability of failure that capacity $D$ is less than demand $d$, i.e. probability of the component reaching its limit state at demand $d$.

Equation (3) is the basic equation calculating fragility and is applicable for all hazards. The demand and capacity in the equation are expressed using parameters having consistent units. The capacity of a component is expressed in terms of a parameter characterizing the demand due to hazard. Examples of this are ground acceleration for seismic ground motion hazard, 3 sec gust wind speed for wind hazard, and water level for flood. The logarithmic standard deviation $\beta_{C}$ represent total variability consisting of aleatory variability and epistemic uncertainties. The aleatory variability is the basic randomness of the system and is taken into consideration in estimating the logarithmic standard deviation $\beta_{R}$. The epistemic uncertainties due to incomplete knowledge are accounted by the logarithmic standard deviation $\beta_{U}$.

Derivation of component fragility is narrowed down to determination of median capacity $D_{m}$; logarithmic standard deviations $\beta_{R}, \beta_{U}$ and $\beta_{C}$. The present paper reviews the available published literature and summarizes methods that are available for derivation of these three fragility parameters of components for different hazards. The paper provides an account of development of seismic fragility calculation starting from inception to current state. The practice of fragility analysis of components against the wind and flood hazards is in nascent stage. With respect to wind fragility analysis, the objective of the present paper is only to summarize the state-of-the-art in wind fragility analysis. For flood hazard, the paper describes tsunami fragility procedures that have been developed till date. The work on high wind and flood PSA started comparatively in recent time, PSA and hazard analysis for these two hazards are briefly discussed for better understanding of the present practice of fragility analysis. The work on EE-PSA of multiple units of NPP in a site has recently been started. This is also briefly discussed. 


\section{FRAGILITY CURVES AND HCLPF CAPACITY OF COMPONENT}

In a typical fragility calculation, the capacity of a component and associated randomness and uncertainties is expressed in terms of the best estimate median capacity $D_{m}$, and two random variables, $\varepsilon_{\mathrm{R}}$ and $\varepsilon_{\mathrm{U}}$ using following expression [Kennedy et al (1980)],

$D=D_{m} \cdot \varepsilon_{R} \cdot \varepsilon_{U}, D=D_{m} \cdot \varepsilon_{R} \cdot \varepsilon_{U}$

Where,

$D_{m}=$ Median capacity expressed in terms of demand parameter $=D^{\prime} \cdot F_{m}$

D: $\quad$ Median value of demand (e.g. peak ground acceleration (PGA) for ground motion hazard due to seismic event);

$\varepsilon_{R}$ : Random variable representing the aleatory variability, i.e. inherent randomness associated with $D_{m}$;

$\varepsilon_{U}$ : Random variable representing the uncertainties due to lack of knowledge associated with $D_{m}$.

$\varepsilon_{R}$ and $\varepsilon_{U}$ are modelled as log-normally distributed random variables, with logarithmic standard deviations of $\beta_{\mathrm{R}}$ and $\beta_{\mathrm{U}}$ respectively and both having unit median. Equation (4) enables to account all randomness and uncertainties in fragility calculation through $\beta_{R}$ and $\beta_{\mathrm{U}}$. With perfect knowledge, the expression for fragility becomes:

$P_{f}(D \leq d)=\varnothing\left[\frac{\ln \left(d / D_{m}\right)}{\beta_{R}}\right]$

$D_{m}$ is also assumed to be lognormally distributed with median of medians and logarithmic standard deviation $\beta_{U}$ to account for the epistemic uncertainties in fragility calculation. The median capacity at a specific confidence level $\mathrm{Q}$ is then:

$D=D_{m} \exp \left\lceil\beta_{U} \emptyset^{-1}(1-Q)\right]$

It may be noted that $95 \%$ confidence (0.95 exceedance probability) median capacity corresponds to a value for which $95 \%$ medians are higher, or 5\% values are lower. Thus the probability of exceedance of true median capacity from the value considered in fragility analysis is 0.95 . Medians are calculated for different confidence levels from equation (7). $P_{f}$ is then calculated for each median value. This results in a family of fragility curves and is given by [Kennedy and Ravindra, 1984]:

$p_{f}(D \leq d)=\Phi\left(\frac{\ln \left(\frac{d}{D_{m}}\right)+\beta_{U} \Phi^{-1}(Q)}{\beta_{R}}\right)$ 


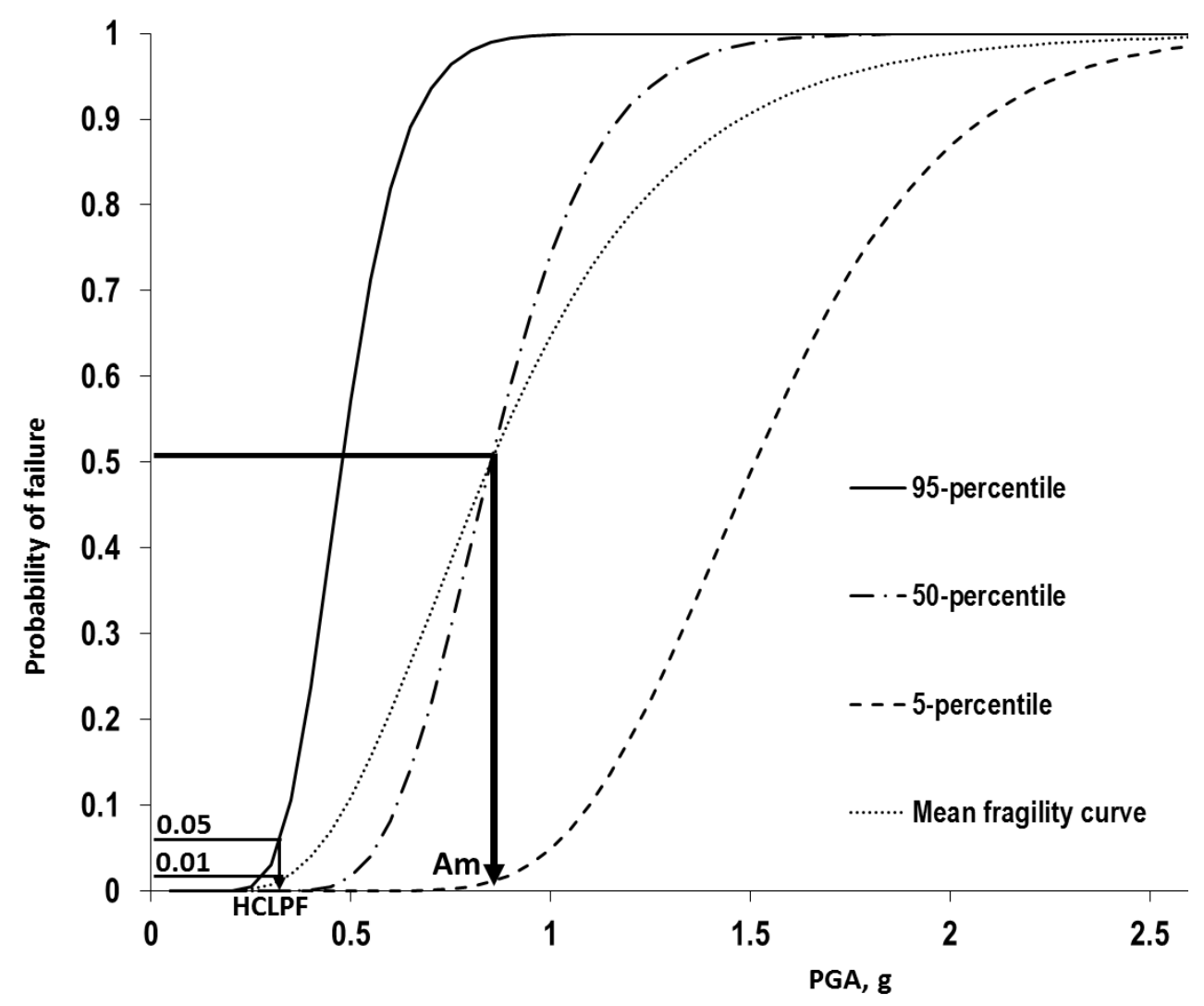

Figure 1. Typical family of fragility curve

The family of fragility curves derived from equation (8) represents failure probability $P_{f}$ for a given demand $d$ at discrete values of non-exceedance probability level (Q) such as $0.05,0.50$ and 0.95 etc. and is given by, The mean fragility curve is:

$P_{f}(D \leq d)=\varnothing\left[\frac{\ln \left(d / D_{m}\right)}{\beta_{C}}\right]$

Where, $\beta_{C}$ represents total variability, i.e. the total standard deviation and is given by:

$\beta_{c}=\sqrt{\left(\beta_{R}^{2}+\beta_{U}^{2}\right)}$

Fig. 1 depicts the generic representation of fragility curve at discrete non exceedance probability of $0.05,0.50$ and 0.95 determined from equation (8) and mean fragility from equation (9). The figure also explains different seismic capacities vis-a-vis fragility curves. The median capacity is defined by equation (5). The so called "High Confidence, Low Probability of Failure" capacity, or "HCLPF" capacity (for example, for seismic events) is the ground acceleration corresponding to about a $5 \%$ probability of failure $\left(P_{f}=0.05\right)$ with $95 \%$ confidence $(\mathrm{Q}=0.95)$ of not exceedance, which is equivalent to $1 \%$ failure probability $50 \%$ non-exceedance probability level, Fig.1. Substitution of $P_{f}=0.05$ and $Q=0.95$ in equations (1) and $P_{f}=0.01$ and $\mathrm{Q}=0.50$ in (3) yield the expressions of HCLPF capacity,

$D_{H C L P F}=D_{m} e^{-1.645\left(\beta_{R}+\beta_{U}\right)}$, or 


$$
D_{H C L P F}=D_{m} e^{-2.326 \beta_{C}}
$$

Equations (8) and (9) and the concept of HCLPF capacity was originally developed for seismic hazard. However, it is applicable for determination of component fragility for other hazards like wind and flood.

\section{System Fragility}

When a SSC of an NPP consists of several elements, its fragility is derived from the element fragility. Similarly, fragility of a system is derived from its component fragility. Equations (8) and (9) provide the element or component fragility. Kennedy et al (1980) describes methodology for determining system fragility from component fragility. Pisharady and Basu, (2010) summarizes method for derivation of system fragility from elements' fragility in to three types. Again, these methodologies are originally developed for seismic fragility, but equally applicable for wind and flood fragility.

\section{SEISMIC FRAGILITY OF NPP COMPONENT}

In seismic fragility evaluation of component, both demand and capacity are expressed as ground acceleration demand $a$, the ground acceleration capacity $A$ and median ground acceleration capacity $A_{m}$. These parameters are defined generally in terms of peak ground acceleration (PGA) of the response spectrum. Fragility curves could also be based on other predominant spectral ordinates. Response based fragility curves had also been proposed for seismic PSA work [Cheng et al. (2013)]. Further discussion on seismic fragility in this paper will be limited to PGA based fragility.

Expressions for seismic fragility of components can be obtained from equations (4) - (11b) replacing $d, D, D_{m}$ and $D_{H C L P F}$ by $a, A, A_{m}$ and $A_{H C L P F}$ respectively. The seismic fragility, i.e. the frequency of component reaching limit state at a given PGA $a$ with non-exceedance probability Q, is as follows [Kennedy and Ravindra, 1984]:

$$
p_{f}=\Phi\left(\frac{\ln \left(\frac{a}{A_{m}}\right)+\beta_{U} \Phi^{-1}(Q)}{\beta_{R}}\right)
$$

The mean fragility is given by:

$P_{f}(D \leq d)=\varnothing\left[\frac{\ln \left(a / A_{m}\right)}{\beta_{C}}\right]$

$\beta_{C}$ is given by equation (10). The HCLPF seismic capacity of component is derived from equations from equations (11a) or (11b) replacing $D_{m}$ by $A_{m}$. Where, $A_{m}$ is calculated from equation (5) replacing $D$ by $A_{G M}$ and $A_{G M}$ is the median PGA of the ground motion.

Calculation of seismic fragility for NPP component basically needs determination of median capacity $A_{m}$ and logarithmic standard deviations $\beta_{R}, \beta_{U}$ and $\beta_{C}$. There are broadly two approaches for calculation of NPP component fragility, i.e. determination of $A_{m}, \beta_{R}, \beta_{U}$ and $\beta_{C}$ : 
1) Fragility method or separation of variable approach, and

2) Hybrid method or CDFM based approach.

The median capacity, and the variability for randomness $\left(\beta_{R}\right)$ and uncertainties $\left(\beta_{U}\right)$ are calculated separately in detailed manner in the first method. In the second method HCLPF capacity is calculated using conservative deterministic failure margin (CDFM) approach and the median capacity with an assumed composite variability $\left(\beta_{C}\right)$ is then calculated. The value of $\beta_{C}$ is taken from experience. The hybrid method is suggested for all components excepting those having high risk significant. Fragility of the components with high risk significant should be calculated by the fragility method or separation of variable approach, others by the hybrid or CDFM based approach.

\section{SEISMIC FRAGILITY OF COMPONENT BY FRAGILITY OR SEPARATION OF VARIABLE APPROACH}

In-depth guidelines for performing a fragility analysis are available in EPRI (2002). This document updates the fragility analysis methodology provided in EPRI TR-103959 [EPRI (1994)] to reflect recent methodological advances in literature; correlates existing methodologies with requirements for the ASME/ANS (2011); and provides implementation guidelines and example problems. This method is termed as 'Fragility Method' in the subsequent discussion in this paper.

Derivation of seismic fragility curves for components principally involves determination of fragility parameters $A_{m}, \beta_{R}$ and $\beta_{U}$, or $\beta_{C}$. From equation (5), determination of median value of safety factor $F$ is key to derive $A_{m}$ once $A_{G M}$ is known. Effort should be made to derive the median value of $F\left(F_{m}\right)$ specific to individual SSC of a plant. There are broadly two classes of methods; direct and indirect, to determine $F_{m}$. Direct method involves either analysis or testing. Indirect method is experience based method (EBM) that maximizes the use of past experience in conjunction with plant walk down [EPRI (1991))]. Table 1 summarizes the categories of components of a typical NPP and corresponding approach generally adopted for their capacity assessment.

Pisharady and Basu (2010) suggested following expression to determine $F$ irrespective method used for component qualification - analytical, or testing, or experienced based methods:

$F=F_{1} F_{2} F_{3}$

$F_{1}$ is a factor representing ratio of capacity to demand, and is a strength factor. $F_{2}$ corresponds to the level of conservatism in assessing capacity; it depends primarily on the energy absorption capacity of SSC beyond elastic limit. $F_{3}$ represents the conservatism associated with calculating demand. Different methodologies for fragility analysis is all about determining the median values of $F_{1}, F_{2}$ and $F_{3}$, and selection of corresponding $\beta *$ (subscript * indicates $R, U$ or $C$ ). As $F_{(.)}$'s follows log-normal distribution, the median $F_{m}$ of " $F$ " is calculated from the median values of $\left\{F_{(.), m}\right\}$

$F_{m}=F_{1, m} * F_{2, m} * F_{3, m}$

There are many sources of variability in estimation of median capacity of SSC. These arise from inherent randomness in the strength of components, dynamic characteristics of the plant systems, and the ability to relate the motion applied to the plant system, at its point of 
Table 1: Typical qualification method of NPP components [Pisharady and Basu (2010)]

\begin{tabular}{|c|c|c|}
\hline NO. & CATEGORY & METHOD OF QUALIFICATION \\
\hline 1. & Reactor core assembly & Analysis \\
\hline 2. & Reactor coolant system vessels (RPV, Pressurizer etc.) & Analysis \\
\hline 3. & Reactor coolant pump & Analysis \\
\hline 4. & Primary coolant piping & Analysis \\
\hline 5. & Large diameter piping & Analysis \\
\hline 6. & Intermediate piping & Analysis \\
\hline 7. & Large vertical storage vessels with formed heads & Analysis \\
\hline 8. & Large vertical storage tank - flat bottom & Analysis \\
\hline 9. & Large horizontal vessels and heat exchangers & Analysis \\
\hline 10. & Small-medium vessels and heat exchangers & Analysis \\
\hline 11. & Buried pipe & Analysis \\
\hline 12. & Large vertical centrifugal pumps with motor drive & Analysis/EBM* \\
\hline 13. & Large vertical pumps & Analysis/EBM \\
\hline 14. & Motor driven compressors & Analysis/EBM \\
\hline 15. & LMOV'S (Large motor operated valves) & Analysis/EBM \\
\hline 16. & Large relief and check valves & Analysis/EBM \\
\hline 17. & Small valves & Analysis/EBM \\
\hline 18. & Hydraulic and air operated valves & Analysis/EBM \\
\hline 19. & Emergency AC power (Diesel generators) & Testing/EBM \\
\hline 20. & Emergency DC power (Batteries on racks) & EBM \\
\hline 21. & Switchgear & Testing/EBM \\
\hline 22. & Dry transformers & Testing/EBM \\
\hline 23. & Control panels and racks (Floor mounted) & Testing/EBM \\
\hline 24. & Instrumentation panels & Testing/EBM \\
\hline 25. & Auxiliary relay cabinets & Testing/EBM \\
\hline 26. & Local instruments & Testing/EBM \\
\hline 27. & Motor control centers & Testing/EBM \\
\hline 28. & Invertors & Testing/EBM \\
\hline 29. & Cable trays & Analysis \\
\hline 30. & Breaker panels & Testing/EBM \\
\hline 31. & Air handling units & Testing/EBM \\
\hline 32. & Ductwork & Analysis \\
\hline 33. & Control rods and drives & Analysis/testing \\
\hline 34. & Ceramic insulators & Testing/EBM \\
\hline 35. & Dampers, diffusers, extractors & Testing/EBM \\
\hline 36. & Battery chargers & Testing/EBM \\
\hline 37. & Civil engineering structures & Analysis \\
\hline
\end{tabular}


attachment to the plant structures, to the ground acceleration. Uncertainties also arise in the functional form of the fragility model itself, whether the supporting data are based on generic or plant-specific data, the manner in which inelastic behavior and energy dissipation is taken into account, and whether the possibility of design/construction errors is included. In the last thirty years, number of NPPs was re-evaluated and wealth of experience is available in this area [Budnitz et al (1984)]. There are also references available for determination of $\beta_{*}$ adopting analytical methods like Monte Carlo simulation technique [EPRI (1994)]. In addition generic values of $\beta *$ are available from literature. $\beta_{\mathrm{F}, *}$ is derived from $\beta_{(.), *}$,

$\beta_{F, *}=\sqrt{\beta_{1, *}^{2}+\beta_{2, *}^{2}+\beta_{3, *}^{2}}$

\section{Fragility parameters of components qualified by analysis:}

\section{$F_{1}$ : Strength factor ' $F_{S}$ '}

The strength factor, $F_{S}$, is the ratio of ultimate capacity to the demand calculated at $A_{G M}$ level and is given by,

$F_{1, m}=F_{s, m}=\frac{S_{m}-R_{N}}{R_{T}-R_{N}}$

Where, $F_{1, m}$ and $F_{s, m}$ are median values of $F_{1}$ and $F_{S}$ respectively. $S_{m}$ is the median value of resistant capacity of an element/component for a given failure mode. $R_{\mathrm{N}}$ is the response of element/component for the specified failure mode against normal operating load (i.e. dead load, operating temperature load, etc.), and $R_{T}$ is the response of element/component for the specified failure mode against total load (sum of seismic and normal operating load).

\section{Strength factor for civil engineering structures}

Civil engineering structures of NPP are assemblage of a number of elements like beam, column, slab, wall etc. Definition of failure could be considered either from strength or from deformation. Derivation of fragility from strength consideration involves with element level failure; an element reaching limit state of strength (or stress). In a highly indeterminate structural system like civil engineering buildings, failure of one element will not lead to total structural failure. Fragility derivation from element strength (or stress) consideration would result in a conservative estimate. Deflection could be a better parameter for this purpose, as through this parameter global behavior of structure is represented well than that by induced stress in element. Pisharady and Basu (2010) illustrated how $F_{s, m}$ could be derived from equation (17) adopting either deflection at specified location or inter-story drift determined by pushover analysis.

\section{Strength factor for mechanical structures and equipment}

Strength factor for mechanical structures and equipment can be derived using equation (17) by substituting the median value of permissible stresses/displacements for ' $S$ ' and the median value of developed stresses/displacements due to normal operating loads and total loads for ' $\mathrm{R}_{\mathrm{N}}$ ' and ' $\mathrm{R}_{\mathrm{T}}$ '. However, it needs to be understood that the values of permissible stresses provided by codes/standards like ASME are not median values, but generally the 95 percentile values. Use of these values will generally result in a very conservative estimation 
Table -2 : Median values, $\beta_{R}$ and $\beta_{U}$ of $F_{S}$ for civil engineering and mechanical structure.

\begin{tabular}{|l|c|c|c|}
\hline \multirow{2}{*}{ SSC } & Median factor of safety, & \multicolumn{2}{|c|}{$\beta_{\mathrm{S}, *}$} \\
\cline { 3 - 4 } & $\mathrm{F}_{\mathrm{S}}$ & $\beta_{\mathrm{S}, \mathrm{R}}$ & $\beta_{\mathrm{S}, \mathrm{U}}$ \\
\hline Civil engineering structures & From equation (9) & $0.06-0.12$ & $0.12-0.18$ \\
Mechanical structures & & 0.11 & 0.11 \\
- RPV & & 0.14 & 0.19 \\
- Reactor internals & & 0.10 & 0.10 \\
- Steam Generator & From equation (9) & 0.10 & 0.14 \\
- Pressurizer & & 0 & 0.36 \\
\hline
\end{tabular}

Note: Values of $\beta_{\mathrm{S}, *}$ are reproduced from Kennedy and Ravindra (1984).

of median capacity. Kennedy and Ravindra (1984), explained an approach to establish the median strength factor for piping by using of equation (17).

Table 2 contains summary of $F_{s}$ and corresponding values of $\beta_{R}$ and $\beta_{U}$.

$F_{2}$ : Inelastic energy absorption factor, ' $F_{\mu}$ ':

The inelastic absorption factor, $F_{\mu}$ accounts for the fact that an earthquake represents a limited energy source and many structures or equipment are capable of absorbing substantial amounts of energy beyond yield without loss-of-function. This aspect introduces conservativeness in seismic capacity and is accounted by $F_{\mu}$.

EPRI, (1994) and Cover et al., (1983) adopted slightly different approach, in which $F_{\mu, m}$ depends on the assumed degree of damping and is given by:

${ }^{-} F_{2, m=} F_{\mu, m}=(\rho \mu-q)^{r}$

Where, $\rho=q+1 ; q=3.00 \delta^{-0.30} ; r=0.48 \delta^{-0.08} ; \mu$ is the system ductility and $\delta$ is the $\%$ of critical damping.

$F_{3}$ : Response conservatism factor ' $F_{R}$ '

Third factor $F_{3}$ is the response conservatism factor, $\mathrm{F}_{\mathrm{R}}$, consists of two parts; factor $\mathrm{F}_{\mathrm{RS}}$ for primary structure and factor $\mathrm{F}_{\mathrm{RE}}$ for equipment structure;

$F_{3, m}=F_{R, m}=F_{R E, m} * F_{R S, m}$

Civil engineering structures, which support and house the equipment and other SSC, are the primary structure and $F_{3}$ or $F_{R}$ consists of only $\mathrm{F}_{\mathrm{RS}}$ and is given by [Kennedy and Ravindra (1984)]:

$F_{3, m}=F_{R, m}=F_{R S, m}=F_{S A, m} * F_{S S, m} * F_{\delta, m} * F_{M, m} * F_{M C, m} * F_{E C, m} * F_{S D, m}$

Where,

$\mathrm{F}_{\mathrm{SA}}: \quad$ Factor for ground motion and associated response spectra for a given PGA.

FS: $\quad$ Soil structure interaction factor. 
$\mathrm{F}_{\delta}: \quad$ Factor for energy dissipation i.e. damping.

$\mathrm{F}_{\mathrm{M}}: \quad$ Structural modeling factor.

$\mathrm{F}_{\mathrm{MC}}$ : Factor for combination of modes and earthquake analysis results.

$\mathrm{F}_{\mathrm{EC}}: \quad$ Factor for combination of earthquake components

$\mathrm{F}_{\mathrm{SD}}$ : Factor to reflect reduction of seismic input with depth.

$F_{3}$ or the response conservatism factor, $\mathrm{F}_{\mathrm{R}}$, consists of $F_{R S}$, and $F_{R E}$ for of mechanical structures and equipment [Kennedy and Ravindra (1984), Kennedy et al.(1982)].

$$
\begin{aligned}
& F_{R E, m}=F_{Q M, m} * F_{S A, m} * F_{M, m} * F_{\delta, m} * F_{M C, m} * F_{E C, m} \\
& F_{R S, m}=F_{S A, m} * F_{\delta, m} * F_{M, m} * F_{S S, m}
\end{aligned}
$$

In equations (21a) and (21b), $F_{Q M}$ is a factor for qualification method and $F_{S A}$ is associated with floor response spectra. Definition of other parameters is same as that of equation (20) but corresponding to mechanical component/equipment under consideration.

Tabulation of values for median values of $\left\{F_{(.), m}\right\}$ 's pertaining to response factors are documented in Kennedy et al. (1980). However, Kennedy and Ravindra (1984) opined that the value in the above reference is for old generation NPP, and suggested the corresponding uncertainties for a modern NPP. The values suggested by them were used successfully in seismic PSA of various NPPs. Subsequently, EPRI (1994) gives a detailed treatment regarding the methodology for determination of $\left\{F_{(.)}\right\}$'s corresponding to response factor. Kennedy et al.(1982) provided a detailed treatment of the methodology for deriving $\left\{F_{(.), m}\right\}$ 's for mechanical components. These values are also in agreement with those suggested by Kennedy and Ravindra (1984) for mechanical components.

After survey of literature, the treatment provided in EPRI (1994) is found preferable to calculate $F_{3}$. However, this calls for a detailed analysis for each parameter. In situations, where such detailed treatment is not practical, the values suggested by Kennedy and Ravindra (1984) may be adopted.

$F_{3, m}=F_{R E, m} * F_{R S, m}$ and $F_{(\#), m}=\Pi F_{(.), m}$

Where subscript (\#) represents RE and RS; the parameters indicated by subscript (.) are the factors to be considered in the applicable equation (20), or (21a) and (21b).

\section{Logarithmic standard deviation $\beta($.}

Estimation of variabilities associated with these factors, i.e. the logarithmic standard


available in literature. $\beta_{(.)}$,* of major factors may be taken from Kennedy and Ravindra (1984). Once $\beta_{(.), *}$ are known, $\beta_{\#, *}$ of $\mathrm{F}_{\mathrm{RE}}$ and $\mathrm{F}_{\mathrm{RS}}$ are derived from

$$
\beta_{\#, *}=\sqrt{\sum \beta_{(.), *}^{2}}
$$


Where, subscript (\#) represents RE and RS.

A survey of the variabilities associated with the median factor of safety was carried out by Park et al. (1998). Variabilities for plants where seismic fragilities are estimated based on scaling of analysis results carried out during design stage [Cover et al. (1983)] and those where additional analysis were carried out as part of seismic PSA is tabulated in this publication. This publication also contains the values for $\beta *$ representing the overall uncertainties based on method of seismic qualification of the component. These values are reproduced in Table 3.

Table 3: Generic values of logarithmic standard deviation based on method of qualification [Park et al., 1998]

\begin{tabular}{|l|l|c|c|}
\hline No. & Method of qualification & $\beta_{\mathrm{U}}$ & $\beta_{\mathrm{R}}$ \\
\hline 1 & Test & 0.30 & 0.33 \\
\hline 2 & Analysis & 0.39 & 0.30 \\
\hline 3 & Experience based method & 0.33 & 0.21 \\
\hline
\end{tabular}

It is suggested that the values of values for $\beta_{(.), \mathrm{R}}$ and $\beta_{(.), \mathrm{U}}$ should be associated with the corresponding $\left\{F_{(.), \mathrm{m}}\right\}$ 's to the extent possible. In situations, where this is not possible, it will be a reasonable approximation to use the uncertainty values, suggested by Park et al. (1998) on the basis of method of component qualification.

\section{Fragility parameters for components qualified by testing:}

In seismic qualification by testing, a component is subjected to input motion on a shake table. Test response spectrum (TRS) is developed from the actual time history of the motion of the shake table generated from the input motion. The input motion is specified by the required response spectrum (RRS). RRS could be the floor response spectra at the location where the component is mounted when a plant specific test is carried out or a general spectrum like the performance level spectrum provided in IEEE (1997) for a generic test. Seismic test of SSC is of two types.

(i) Qualification test: This is the test with respect to RRS. TRS is compared with RRS. The component is qualified, if it continues to perform its intended function when the TRS envelops the RRS.

(ii) Fragility test: This class of test is continued till the SSC fails.

Equations (14) and (15) are applicable to calculate median safety factor of component qualified by both types of test. Pisharady and Basu (2010) summarized the approaches for deriving fragility parameters from the results of tests.

Seismic fragility of components evaluated by qualification tests:

The strength factor $F_{1}$ of equation (8) is expressed in general form as follows:

$F_{1}=\propto \tau$ 
Where, $\alpha$ is a factor to account for narrow band spectra, conservative demand and capacities; $\tau$ is the ratio of capacity spectra and demand spectra. There are more than one method for determination of $\alpha$ and $\tau$ as well as $F_{2, m}$ and associated logarithmic standard deviation. $F_{3, m}$ can be calculated using the approach similar to that of analytical method.

Method - 1

$\tau$ is equivalent to the factor $F_{E D}$ of the method developed by Lawrence Livermore National Laboratory (LLNL) [Salmon and Kennedy (1994)]. The seismic capacity spectrum (SCS) and in-structure response spectrum (ISRS) are TRS and RRS respectively. According to Salmon and Kennedy (1994), no correction factor for narrow banded spectra or conservative demand and capacity is necessary, hence $\alpha$ is taken as 1.0, and $\tau$ is determined from the following expression:

$\tau=\frac{T R S}{R R S}$

If the dynamic behavior of the component is in the rigid frequency range then $\tau$ is given by: $\tau=\frac{T R S_{Z P A}}{R R S_{Z P A}}$

$T R S_{Z P A}$ and $R R S_{Z P A}$ are the zero point acceleration (ZPA) values of TRS and RRS respectively. Otherwise, there exists more than one approach to determine $\tau$. If the predominant frequency of a component is known, then $\tau$ can be determined from spectral ordinates of TRS and RRS corresponding to that frequency:

$\tau=\frac{T R S_{m}}{R R S_{m}}$

Where, $T R S_{m}$ and $R R S_{m}$ are the spectral ordinates of TRS and RRS respectively corresponding to the predominant frequency. However, in most cases a component has multiple predominant frequencies. In such case, one approach could be the minimum ratio,

$\tau=\operatorname{Min}\left\{\left[\frac{T R S_{i}}{R R S_{i}}\right]\right\}$

$T R S_{i}$ and $R R S_{i}$ are spectral ordinates of TRS and RRS respectively corresponding to $i^{\text {th }}$ predominant frequency. Eqn. (28) will estimate $\tau$ very conservatively. A better estimate of $\tau$ can be the ratio of area enclosed by TRS to the area enclosed by RRS within the predominant frequency range.

$\tau=\frac{\int_{f_{p}} T R S}{\int_{f_{p}} R R S}$

The nominator and denominator of the right hand side of equation (29) are similar to the acceleration spectrum intensity [Kramer (2007)]. Table 4 contains the suggested range of predominant frequency of some important NPP components.

An approximation of $F_{2}$ could be $F_{E C}$, which results in its value as 1.4 . The assumption herein is that TRS is equivalent to the capacity spectrum of the EBM, which will in most cases lead to a conservative result. Salmon and Kennedy (1994) specifies the value of $F_{E C}$ as 1.40, which is suggested for $F_{2}$. The associated logarithmic standard deviation $\beta_{C}$ is 0.20 .

The approach similar to that of analytical method may be used to calculate $F_{3, m}$. However, in absence of detailed assessment, the $F_{3, m}$ can be taken as 1.28 with $\beta_{C}$ as 0.35 [Salmon and Kennedy (1994)]. 
Table 4: Typical frequency range of NPP Components [Pisharady and Basu (2010)]

\begin{tabular}{|c|c|c|}
\hline No. & Category & Frequency range (hz) \\
\hline \multicolumn{3}{|c|}{ 1. Reactor core assembly } \\
\hline 2. & $\begin{array}{l}\text { Reactor coolant system vessels (RPV, Pressurizer } \\
\text { etc.) }\end{array}$ & $3-10$ \\
\hline 3. & Reactor coolant pump & $5-15$ \\
\hline 4. & Primary coolant piping & $1.0-33$ \\
\hline 5. & Large diameter piping & $1.0-33$ \\
\hline 6. & Intermediate piping & $1.0-33$ \\
\hline 7. & Large vertical storage vessels with formed heads & \\
\hline 8. & Large vertical storage tank - flat bottom & \\
\hline 9. & Large horizontal vessels and heat exchangers & $4-10$ \\
\hline 10. & Small-medium vessels and heat exchangers & $4-10$ \\
\hline 11. & Buried pipe & $1-33$ \\
\hline 12. & Large vertical centrifugal pumps with motor drive & $20-50$ \\
\hline 13. & Large vertical pumps & $5-15$ \\
\hline 14. & Motor driven compressors & $20-50$ \\
\hline 15. & LMOV'S (Large motor operated valves) & \\
\hline 16. & Large relief and check valves & \\
\hline 17. & Small valves & $20-50$ \\
\hline 18. & Hydraulic and air operated valves & \\
\hline 19. & Emergency AC power (Diesel generators) & $20-50$ \\
\hline 20. & Emergency DC power (Batteries on racks) & $7-15$ \\
\hline 21. & Switchgear & $5-10$ \\
\hline 22. & Dry transformers & $5-10$ \\
\hline 23. & Control panels and racks (Floor mounted) & $5-10$ \\
\hline 24. & Instrumentation panels & $5-10$ \\
\hline 25. & Auxiliary relay cabinets & $5-10$ \\
\hline 26. & Local instruments & \\
\hline 27. & Motor control centers & $5-10$ \\
\hline 28. & Invertors & $5-10$ \\
\hline 29. & Cable trays & \\
\hline 30. & Breaker panels & $5-10$ \\
\hline 31. & Air handling units & \\
\hline 32. & Ductwork & $20-50$ \\
\hline 33. & Control rods and drives & $5-50$ \\
\hline 34. & Ceramic insulators & \\
\hline 35. & Dampers, diffusers, extractors & $20-50$ \\
\hline 36. & Battery chargers & $5-10$ \\
\hline 37. & Civil engineering structures & \\
\hline
\end{tabular}


Method - 2

This method for determination of $\alpha, \tau$ and $F_{2}$ are adopted from EPRI (1994). This document stipulates formulations for cabinet based tests and device based tests. For both these cases, $\tau$ is given by equation (34) and determination of $\tau$ is similar to the approaches described in Method -1 . In this method, $\alpha$ is the correction factor for narrow band spectra, is represented in the following form:

$\alpha=\frac{C_{T} C_{I}}{C_{C} D_{R}}$, for cabinet based test

$\alpha=\frac{C_{T} C_{I}}{C_{C} \frac{A F_{C}}{F_{M S}} D_{R}}$, for device based test

Where,

$\mathrm{C}_{\mathrm{C}} \quad$ : Clipping factor for narrow banded demand

$\mathrm{C}_{\mathrm{T}} \quad$ : $\quad$ Clipping factor for narrow banded TRS

$\mathrm{C}_{\mathrm{I}} \quad$ : Capacity increase factor

$\mathrm{D}_{\mathrm{R}} \quad: \quad$ Demand reduction factor

$\mathrm{AF}_{\mathrm{C}} \quad: \quad$ Cabinet amplification factor

$\mathrm{F}_{\mathrm{MS}} \quad: \quad$ Multi axis to Single axis conversion factor

Method to determine the median values of these factors and their related uncertainties is outlined in EPRI (1994).

The factor, $F_{3, m}$ is similar to the broadened input spectrum device capacity factor $\left(F_{D}\right)$ of EPRI (1994). This factor depends on the level of conservatism that is judged to exist in the TRS based on the testing methods that were used. Generic values of median capacity and logarithmic standard deviation for this factor depending on the type of data source are given in EPRI (1994).

$F_{3, m}$ can be calculated using the approach similar to that of analytical method.

Out of the above approaches explained above, Method - 2 based on the EPRI (1994) approach addresses different scenarios adequately. EPRI methodology has been referenced in the ASME/ANS PRA Standard on EE-PSA [ANS (2005)].

Components evaluated by fragility testing:

The TRS at failure represents "fragility level" (or ruggedness) of the component. The difference between the fragility level and qualification level thus represents the seismic margin or reserve capacity of the component. Literature on fragility tests are only a handful. The lowest ratio of TRS at failure to RRS over the frequency range of interest will provide the median factor of safety for the component, i. e.

$$
F_{m}=\alpha * \text { Lowest }\left[\frac{T R S_{\text {failure }}}{R R S}\right]
$$


Where, $\alpha=0.8$

Derivation of fragility curve can be accomplished using $F_{m}$ of equation (32) and the logarithmic standard deviations $\beta_{R}$ and $\beta_{U}$ given in Table 3.

\section{Fragility parameters for components qualified by indirect method:}

Seismic qualification of components by indirect method maximizes the use of past experience in conjunction with walk down screening evaluation process for capacity assessment. Items that pass the screen are considered to possess adequate capacity. Items not passing the screen are of concern and fragility analysis is necessary depending on the potential risk. Equations (5) and (15) are applicable for determination of median capacity of component qualified by indirect method.

The factors $F_{1}$, can be determined from equation (24). The basis for deriving $\alpha$ and $\tau$ for components qualified by indirect method could be adapting the method developed by Lawrence Livermore National Laboratory (LLNL) [Salmon and Kennedy (1994)]. $\alpha$ is taken as 1.0 and, $\tau$ is equivalent to the factor $F_{E D}$ and can be determined from the following expression:

$$
\tau=\frac{S C S}{S D S}
$$

Where, SCS is the seismic capacity spectrum, which is a representation of seismic capacity and is generally defined by either of reference spectrum or generic equipment ruggedness spectrum [DOE (1977)]. SDS is seismic demand spectrum, which is equivalent to the RRS in case of testing. $\tau$ may be evaluated in similar manner of equations (25) to (29) in which TRS is replaced by SCS and RRS by SDS.

The factor $F_{2}$ is similar to the factor $F_{E C}$ of Salmon and Kennedy (1994), which is the ratio of the ground motion level at which the component ceases to perform its intended function to the experience data capacity spectrum (herein the reference spectrum or GERS). The values of $F_{E C, m}$ as specified in Salmon and Kennedy (1994) and the associated uncertainty $\beta_{c}$ are tabulated in Table 5. These values are suggested for $F_{2, m}$.

$F_{3, m}$ can be evaluated adopting approach for $F_{3}$. However, in absence of detailed assessment, $F_{3, m}$ can be taken as 1.28 with a composite uncertainty $\beta_{C}$ as 0.35 [Salmon and Kennedy (1994)].

Table 5: Median value of factor $F_{2}$ [Salmon and Kennedy, 1994]

\begin{tabular}{|l|l|c|}
\hline \multicolumn{1}{|c|}{ Spectrum used to define capacity } & $\begin{array}{c}\mathrm{F}_{2} \\
\left(\mathrm{~F}_{\mathrm{EC}}\right)\end{array}$ & $\beta_{\mathrm{C}}$ \\
\hline Reference spectrum & 2.35 & $0.30-0.60$ \\
\hline GERS (Non-relay) & 1.49 & 0.25 \\
\hline GERS (relay) & 1.07 & 0.20 \\
\hline
\end{tabular}




\section{SEISMIC FRAGILITY BY HYBRID METHOD OR CDFM BASED APPROACH}

The hybrid method or CDFM based approach has been developed on the observation that annual probability of unacceptable performance for any component is relatively insensitive to $\beta_{c}$. This annual probability (seismic risk) can be computed with adequate precision from the conservative deterministic failure margin (CDFM) capacity and estimate of $\beta_{c}$ [EPRI (2012)]. $\beta_{c}$ may further be divided to $\beta_{R}$ and $\beta_{U}$ for obtaining the family of fragility curves, Fig.1. In some literature the CDFM capacity is also referred as HCLPF capacity by CDFM method ( $A$ CDFM-HCLPF) or $\mathrm{C}_{1 \%}$ capacity. Pisharady and Basu (2010) suggested a similar concept of deriving the family of fragility curve using HCLPF capacity determined by CDFM method.

The CDFM capacity of a component is computed using realistic material and response parameters but taking credit of conservatively defined failure capacity (code equation) and limited inelastic absorption capacity of structures and components [Prassinos et al (1986)]. The CDFM capacity of a component is given by:

$A_{C D F M-H C L P F}=F_{S} * F_{\mu} * A_{G M}$

Where, $A_{C D F M-H C L P F}$ is component HCLPF capacity determined by CDFM method, and

$$
F_{s}: \quad \frac{S-R_{N}}{R_{T}-R_{N}}
$$

$S: \quad$ Resistance capacity of the element for a given capacity.

$R_{T}$ and $R_{N}$ are defined in equation (17).

$\beta_{c}$ is derived based on experience. It is observed from literature that typical range of $\beta_{c}$ is 0.3 0.6 . As the random variability is principally due to ground motion a constant $\beta_{R}$ value is suggested in literature [EPRI (2012)]. The value of $\beta_{U}$ can be calculated from equation (10) using the values of $\beta_{c}$ and $\beta_{R}$. Once HCLPF capacity of component and $\beta_{c}$ are known, $A_{m}$ is calculated from equation (11b). The family of fragility curves can then be derived from equation (12) from the values of $\beta_{R}$ and $\beta_{U}$ derived from assumed values of $\beta_{c}$ and calculated values of $A_{m}$.

The recommended values of $\beta_{c}, \beta_{R}, \beta_{U}$ and ratio of $A_{C D F M-H C L P F}$ and $A_{m}$ are given in Table 6 [EPRI (2012)]. The recommended $\beta_{c}$ value is slightly conservative. A constant $\beta_{R}$ value of 0.24 is recommended owing to the observation that the random variability is principally due to ground motion.

\section{WIND FRAGILITY OF NPP COMPONENTS}

Wind fragility is defined as the conditional probability of failure of an SSC as a function of wind speed. Typically, a family of fragility curves corresponding to a particular failure mode is developed. A lognormal model is typically used to represent the fragility with the parameters of the median wind-speed capacity $\left(V_{m}\right)$ and the logarithmic standard deviation $\beta_{R}$ representing randomness in capacity; the uncertainty in median capacity is also modelled as a lognormal variable with unit median and the logarithmic standard deviation $\beta_{U}$. The generic equations (4) through (11b) could be used with appropriate modifications. 
Table 6: Recommended values of $\beta_{c}, \beta_{R}, \beta_{U}$ and ratio of $A_{C D F M-H C L P F}$ and $A_{m}$ for use in Hybrid Method [EPRI (2012)]

\begin{tabular}{|l|c|c|c|c|}
\hline \multicolumn{1}{|c|}{ Type of SSC } & $\beta_{c}$ & $\beta_{R}$ & $\beta_{U}$ & $A_{C D F M-H C L P F} / A_{m}$ \\
\hline $\begin{array}{l}\text { Structures \& major passive } \\
\text { mechanical components mounted } \\
\text { on ground or at low elevation } \\
\text { within structures }\end{array}$ & 0.35 & 0.24 & 0.26 & 2.26 \\
\hline $\begin{array}{l}\text { Active components mounted at } \\
\text { high elevation in structures }\end{array}$ & 0.45 & 0.24 & 0.38 & 2.85 \\
\hline Other SSCs & 0.40 & 0.24 & 0.32 & 2.54 \\
\hline
\end{tabular}

Wind loading effects include the aerodynamic forces produced by the dynamic pressure component of the wind flow, the associated atmospheric pressure change (APC) within the core (for tornado), and impact forces produced by missiles (i.e., objects picked up and accelerated by the wind field). These wind loading effects may damage the building housing the equipment of interest or the equipment itself if it is exposed.

The analysis of fragility for a SSC depends on the definition of failure modes and the potential interaction of individual failure modes as discussed later.

The major tasks in wind fragility analysis are:

- Selection of SSCs

- Plant walk down

- Missile survey

- Screening of SSCs

- Fragility analysis for wind pressure

- Fragility analysis for missile impact

\section{Selection of SSCs}

The systems analyst and the fragility analyst should interact with each other to develop a list of SSCs to be included in the wind PSA. These could be electrical equipment, mechanical equipment and piping that are housed within the buildings and outdoor equipment such as tanks.

\section{Plant Walk down}

Plant walk down focuses on the SSCs; buildings that house these SSCs are examined for their existing conditions. If there are doors and openings in the buildings, the analyst will note them for inclusion in the missile risk analysis. Walk down is used to look for potential spatial interactions between buildings, collapse of stacks and block walls on to SSCs. Based on recent studies, the analyst should pay particular attention to metal clad buildings especially to the connection of cladding to the structural framing. 


\section{Missile Survey}

A survey of the plant buildings and their surroundings is made to assess the number and types of objects that could be picked up by a tornado and could become potential missiles. These could be tree, metal siding, auto trailer, steel pipe, tool box etc. For details on how this survey is done to provide input to missile risk analysis the reader is referred to Twisdale (1988) and Twisdale and Vickery (1995).

\section{Screening of SSCs}

Based on the plant wind design criteria and using the results of the plant walk down, the analyst will screen out certain items from the SSC list; these could be housed in reinforced concrete Seismic Category 1 structures designed to withstand a design basis tornado. SSCs housed in non-category I metal clad buildings (e.g., turbine building) or near unprotected openings are reviewed to verify that the potential missiles cannot impact them before the SSCs are screened out.

\section{Fragility Analysis for Wind Pressure}

For the remaining SSCs (including any buildings), the fragility for wind pressure is evaluated as described below:

The analysis includes an assessment of each individual failure mode that can produce failure of a SSC. These include:

(i) Wind pressure loads (including APC as appropriate)

(ii) Missile loads

(iii)Structural interaction failures

Extreme winds and wind-borne debris are correlated loadings. The higher the wind speed, the greater are the number and energy of the wind-borne missiles. Many missiles will impact large SSCs. Hence, a key fragility analysis consideration is to treat simultaneously wind and missile loading.

Failure modes include failure of walls, overturning, sliding and collapse as well as missile penetration and scabbing of concrete. Fragility parameters are estimated for each of the credible failure modes of the SSC. Failure of structures could be overall, such as failure of a shear wall or moment resisting frame, or local, such as out-of-plane wall failure or pull-off of metal siding. Wind pressure loading is based on the methodology contained in design standards [ASCE (2010)]. The effect of wind-borne missiles on SSCs can be found in [Twisdale (1988)]. The development of fragility curves for structures is done in terms of the factor-of-safety, defined as the resistance capacity divided by the response associated with the design-basis loads from extreme winds. The variability of the factor-of-safety depends on the variability of strength capacity and the response to specified loads. Wind capacity is modelled as a product of random variables and is expressed in terms of wind speed. Besides the strength characteristics, the capacity of a structure for the effects of wind pressure also depends on a number of factors affecting wind pressure/force relationship. For example, shielding effects of various structures at the site results in an increase of wind speed through a constricted space or a decrease where it may be slowed down due to obstructions. Such funneling characteristics describing the channeling of winds around structures have a very 
important influence on the wind forces. The actual forces are also determined by the structural shapes because wind pressure and forces are related to the wind velocity by a shape factor. Another factor important in this regard is the vertical distribution of wind velocity, which is a function of terrain roughness. Examples of the development of wind fragilities for structures can be found in references [Reed and Ferrell (1987), Ravindra et al (1997), Twisdale and Vickery (1995)].

Recently, a code-based approach using load and resistance factors for wind fragility evaluation has been proposed by Twisdale and his co-researchers [ARA (2014)].

Most nuclear power plant structures have substantial wind resistance if the original design basis had included extreme wind loading. Major vulnerabilities have sometimes been identified for non-seismic category structures due to their potential for collapsing on safetyrelated structures or equipment. These structures include exhaust stacks, unprotected walls, outside wiring and cabling, etc. Similarly, many older plants have safety-related equipment such as tanks and equipment located outdoors that are vulnerable to wind-borne missiles. They should be identified during the walk down.

$\mathrm{n}$ analyzing the failure of indoor equipment (within the structures), it may be conservatively assumed that the failure of a structure causes the failure of all equipment within the structure. It is possible that the structure may not collapse, but the indoor equipment may still be damaged from pressure drop due to passage of a tornado. This damage occurs because of inadequate venting in the structure. There is a rapid pressure drop due to passage of a tornado, and this results in escape of air from the building; if the exit is not rapid enough, it causes internal pressure. This pressure might lead to failure of block walls, which could collapse onto safety-related structures. Indoor equipment is also susceptible to damage from missiles entering through louvres, vents, etc. Damage to internal SSCs may also be caused by wind-induced pressurization through openings in the structure.

Wind fragility depends on the original design basis of the nuclear plant. In some countries, the wind design includes tornado or hurricane (typhoon) or both. The structures in these nuclear power plants should have large median wind speed capacities. In addition, concrete structures designed to resist seismic loading will have inherent resistance to wind loading. The analyst should take advantage of this in screening out buildings and SSCs they support.

For the remaining buildings and outdoor SSCs, the plant specific wind fragilities are developed.

\section{Fragility Analysis for Missiles}

Typically a simulation procedure is used to model the injection of objects into the tornado wind field, tracking them along the path of the tornado and ejection onto SSCs (called "targets"). TORMIS software does this for a large number of tornadoes representing the tornado hazard at the site. The fragility of the target for missile impact is evaluated taking into account the protection offered by the barriers i.e., walls and roofs of buildings and the protection by the location of the target (e.g., behind walls and away from openings etc.). For details, the reader is referred to Twisdale and Vickery (1995). 


\section{Wind Plant Response Analysis}

The wind PSA systems model includes wind-caused initiating events and other failures that can lead to core damage or large early release. Typically, the wind PSA systems model is adapted from the internal events PSA systems model by incorporating the wind-analysis aspects that are different from the corresponding aspects in the internal events PSA systems model. Further, the analysis consists of developing event trees and fault trees in which the initiating event can be either the extreme wind effect itself or a transient induced by the extreme winds. Various accident sequences that lead to core damage (Level 1 PSA) or releases (Level 2 PSA) are identified, and their conditional probabilities of occurrence are calculated. The frequency of core damage or release is obtained by a convolution over the relevant range of wind speeds. Factors to be considered in this analysis include specific wind fragilities of SSCs and non-wind-related unavailability or failures of equipment, operator error, any warning time available to take mitigating steps (e.g., in the case of hurricanes), the possibility of recovery actions by operators and replacements by substitutes to accomplish the needed function, and the likelihood of common-cause failures. Since the wind hazard and wind fragilities are input as families of curves representing the uncertainties, the quantification should properly propagate the uncertainties through the accident sequences to result in uncertainty bounds on CDF and release frequencies such as LERF.

It is important to capture the dependencies among extreme wind caused failures e.g., spatial and environmental dependencies. This is true for a single SSC but the extreme wind could affect multiple SSCs at the same time. Another important consideration is that at higher wind speeds, the fragility of SSCs may be substantial making the probability of "success" much less than one; therefore, excluding these "success" states could lead to erroneous PSA results. An example of systems analysis for extreme winds can be found in [Kaasalainen (2013)].

\section{High Winds PSA Outputs and Uses}

Wind PSA (Level 1 and Level 2) for single reactor units provides estimates of CDF and LERF along with the significant risk contributors. The uncertainty bounds on these CDF and LERF are also developed. These outputs should help in any upgrading decisions if the absolute values of CDF and LERF from wind induced events exceed the acceptable limits.

\section{FLOOD FRAGILITY OF NPP COMPONENT}

This section summarizes the state-of-the-art tsunami fragility practices. Flood hazard caused by a tsunami induces not only static water pressure but also dynamic one thus it includes failure modes due to flood hazard. When the tsunami waves reach the coastal zone, they produce hazardous effects, such as an extreme change of water level, inundation, strong current velocities, hydro-dynamic forces to barrier structures, scour, and debris flow.

AESJ (2011) specifies the technical requirements for performing the tsunami PSA. Mihara et al (2012) also presented the technical procedures for tsunami fragility evaluation of SSCs. Based on the technical background; AESJ (2012) also shows the field investigation of the actual tsunami disaster and application examples for tsunami fragility. Sugino et al (2008) also conducted various tsunami run-up analyses from the wave source and evaluated the fragility curve for inundation failure mode of SSC. Regarding combination fragility between earthquake and tsunami, Mihara et al (2014) categorized the mixed failure modes and 
specified the fragility procedures for tsunami barriers. The state-of-the-art tsunami fragility relating practices described above will be discussed in the following paragraphs.

\section{Accident Scenario Identification}

Accident scenarios will be selected with consideration given not only to accident scenarios reflecting direct damage caused by a tsunami but also to accident scenarios reflecting its indirect impact. They should be selected based on the actual tsunami or flood disaster cases shown in AESJ (2012). Site and plant walk-down is the most important procedures to identify accident scenarios. The key issues to for the site and plant walk-down based on the actual disasters' database are shown in Table 7.

For accident scenarios reflecting direct damage, the following impacts of a tsunami shown in Table 8 will be taken into consideration. The possibility of a tsunami running up along rivers and on land will be also taken into consideration.

For accident scenarios reflecting indirect damage, consideration will be given to various cases depending on site conditions. In those cases, for example, drifting articles flowing out of facilities in the power plant, or drifting articles, such as fishing boats and timber, flowing out of fishing ports, timber basins, etc., due to an earthquake, may collide with the facilities of the power plant.

\section{Tsunami Hazard Analysis}

As the probabilistic tsunami hazard analysis (PTHA) progresses into more detailed run-up and inundation results, one of the key attribute will be the assessment of the impacted SSCs. If the direct or indirect effect of loads on structures can be estimated, the need for establishing the probability of failure of specific buildings may become clearer. Otherwise, it may be appropriate (albeit conservative in some cases) and more effective to assume that certain components within specific buildings (e.g., switchgear rooms, emergency diesel generators) and structures (e.g., tanks) are unavailable in the PSA at specific flood elevation levels (i.e., with a binary probability of $0 \%$ or $100 \%$ depending on the site location with respect to the inundation potential). For components inside buildings, this would depend on the ability of doors and other entrances to maintain interior areas dry from the flooding effects (both static and dynamic). Therefore, any initial indication that the PTHA may provide in terms of elevations that would well exceed the range of credible flooding scenarios can help identify SSCs that would be available even in the most severe magnitude tsunami levels. Conversely, it may help indicate SSCs that would most likely receive minimal credit if significant exposure to the tsunami effects is expected in most scenarios.

The PTHA should be sufficiently complete to provide insights into other potential credible tsunami effects aside from site inundation, such as debris impact, drawdown and sedimentation/scouring. It may be challenging to consider all scenarios in a full probabilistic framework. This may limit the consideration of some of these additional impacts to a deterministic assessment on the credibility of such scenarios in the first place, and the need for their inclusion in the tsunami PSA.

Tsunami fragility evaluation needs not only tsunami height but also various kinds of parameters which will be converted into load effects such as hydrodynamic force, morphological change and collision of drifting debris. Correlation between them from 
Table 7: Key issues for the site and plant walk-down based on the actual disasters [AESJ (2012)]

\begin{tabular}{|c|l|}
\hline No. & \multicolumn{1}{|c|}{ Key issues } \\
\hline 1 & Water tightness of meter gauges and piping penetrations \\
\hline 2 & $\begin{array}{l}\text { Cable runs (cable penetrations), thumps, tunnels, an underground passages, } \\
\text { etc. as an invading route of inundation }\end{array}$ \\
\hline 3 & $\begin{array}{l}\text { Opening-and-closing directions of watertight doors, since water pressure } \\
\text { may be poured to the direction to open the door where its water tightness is } \\
\text { lost depending on the inundation route }\end{array}$ \\
\hline 4 & Water tightness at the foundation part of the seawater pump \\
\hline 5 & Conditions of watertight walls \\
\hline 6 & Water tightness of independent rooms \\
\hline 7 & Confirmation of height of partition walls \\
\hline 8 & Openings, such as sewers for drainage and cable pits \\
\hline 9 & Status of the objects which may be drifting debris \\
\hline 10 & Installation height of outdoor instrument \\
\hline 11 & $\begin{array}{l}\text { Status of not only main buildings such as a reactor building and turbine } \\
\text { building but the pump building, etc. }\end{array}$ \\
\hline 12 & $\begin{array}{l}\text { Pipings, tanks, etc. installed in the outdoors which may be subject to the } \\
\text { influence of tsunami }\end{array}$ \\
\hline 13 & Parts which may be flood courses into a site, such as an access road \\
\hline 14 & Watertight conditions of the fire prevention doors \\
\hline 15 & Actuals conditions in the site of the design water level of the buildings \\
\hline
\end{tabular}

Table 8: Impacts to be considered in accident scenarios reflecting direct damage

\begin{tabular}{|l|l|}
\hline \multicolumn{1}{|c|}{ Impact of tsunami } & \multicolumn{1}{c|}{ Impact on buildings, components, etc. } \\
\hline $\begin{array}{l}\text { Immersion and } \\
\text { inundation of facilities } \\
\text { due to flooding }\end{array}$ & $\begin{array}{l}\text { Damage to dynamic functionality of facilities and } \\
\text { damage to power generation and transmission } \\
\text { functionality of electric facilities }\end{array}$ \\
\hline $\begin{array}{l}\text { Wave power and fluid } \\
\text { force of tsunami }\end{array}$ & $\begin{array}{l}\text { Structural damage of buildings and structures, } \\
\text { components, etc. }\end{array}$ \\
\hline $\begin{array}{l}\text { Movement of seabed } \\
\text { sand }\end{array}$ & Damage to functionality of seawater intake facilities \\
\hline $\begin{array}{l}\text { Drop in water level due } \\
\text { to backrush }\end{array}$ & Damage to functionality of seawater intake facilities \\
\hline
\end{tabular}

tsunami source to each SSC points is also necessary. Ideally, correlation of such parameters will be preferable to be directly calculated from the output of PTHA. Therefore, for most sophisticated PTHA model based on earth science which can evaluate full correlation of each parameter from tsunami source to site specific point, the concept of control point described later is not necessarily required for tsunami PSA.

But, in reality, the concept of control point has to be introduced to evaluate correlation of each parameter from there to site specific point for reasonable PTHA model from engineering point of view. While these results are typically site specific reflecting the topographical and 




Figure 2: Distinctive Elements and Procedures of the PTHA

bathymetrical characteristics of the sea bed between sources and the sites, the location at which the tsunami hazard is evaluated should have a common nature that it will allow to use the assessment results for the analysis of inundation at various points of the plant site that are directly connected to fragility evaluation of SSCs.

Comparing to other external hazards, the distinctive elements and procedures of the PTHA describe above are shown in Figure 2.

\section{Tsunami Fragility Evaluation}

\section{Failure mode}

The failure modes should be extracted for assessment if the corresponding damage may directly or indirectly have a significant impact on the stability of core or reactor containment boundary, due to inundation and immersion, wave power, scouring, collision of drifting 

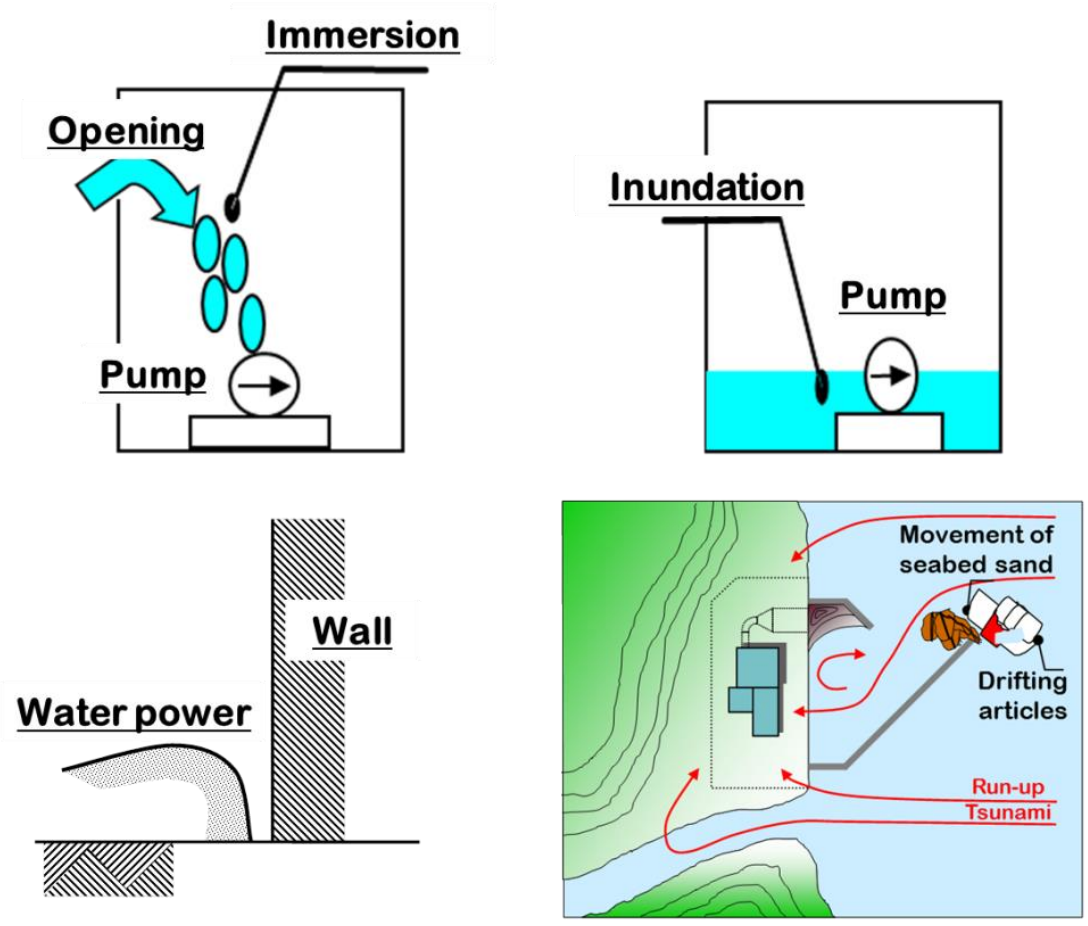

Figure 3: Failure modes caused by tsunami

debris, movement of seabed sand, etc. caused by tsunami events. Examples of failure modes caused by tsunami are shown in Figure 3. For extraction of failure modes leading to structural and functional damage due to scouring or movement of seabed sand, etc., caused by tsunami events, the uplift or subsidence in the surrounding areas of the site assessed in PTHA must be taken into consideration.

\section{Damage Assessment Indexes}

A realistic response quantity that can indicate the degree of damage in the target failure mode should be used as a damage assessment index. Damage assessment indexes should be selected appropriately from physical quantities used for describing the functional loss of buildings, structures and components due to inundation and immersion, wave power, scouring, collision of drifting debris, and movement of seabed sand caused by a tsunami. Those physical quantities include run up, inundation depth, accumulation height, stress, and displacement.

The damage assessment indexes of buildings and structures and those of the components, etc., defined here are different from the tsunami height specifying the horizontal axis of fragility curves. Rather, they refer to indexes used for obtaining the damage probability at which target buildings and target structures will undergo functional loss if a tsunami specified by this tsunami water level inundates or runs up to their locations. Examples of damage assessment indexes corresponding failure modes are shown in Table 9. 
Table 9: Examples of damage assessment indexes (DAI)

\begin{tabular}{|c|c|c|c|c|}
\hline \multicolumn{2}{|c|}{ Facilities } & Failure modes & Threshold & DAI \\
\hline \multirow{5}{*}{ Outdoor } & \multirow{4}{*}{$\begin{array}{c}\text { Seawater } \\
\text { intake system }\end{array}$} & $\begin{array}{l}\text { Structural damage by water } \\
\text { power or collision of } \\
\text { drifting articles }\end{array}$ & $\begin{array}{l}\text { Structural } \\
\text { strength }\end{array}$ & Stress \\
\hline & & Function loss by inundation & $\begin{array}{c}\text { Located } \\
\text { height }\end{array}$ & $\begin{array}{l}\text { Run-up } \\
\text { height }\end{array}$ \\
\hline & & $\begin{array}{l}\text { Loss of cooling water by } \\
\text { backwash }\end{array}$ & $\begin{array}{c}\text { Core cooling } \\
\text { time }\end{array}$ & $\begin{array}{c}\text { Duration } \\
\text { water } \\
\text { level } \\
\text { decrease }\end{array}$ \\
\hline & & $\begin{array}{l}\text { Closed intake by movement } \\
\text { of seabed sand }\end{array}$ & $\begin{array}{l}\text { Intake } \\
\text { height }\end{array}$ & $\begin{array}{c}\text { Sand } \\
\text { deposition } \\
\text { height }\end{array}$ \\
\hline & $\begin{array}{c}\text { Transmission } \\
\text { system }\end{array}$ & Function loss by inundation & $\begin{array}{l}\text { Located } \\
\text { height }\end{array}$ & $\begin{array}{l}\text { Run-up } \\
\text { height }\end{array}$ \\
\hline Indoor & $\begin{array}{c}\text { Core cooling } \\
\text { system }\end{array}$ & $\begin{array}{l}\text { Loss of core cooling and } \\
\text { heat removal function by } \\
\text { building inundation }\end{array}$ & $\begin{array}{c}\text { Located } \\
\text { height }\end{array}$ & $\begin{array}{c}\text { Inundation } \\
\text { height }\end{array}$ \\
\hline
\end{tabular}

Uncertainty of capacity of SSC

The damage limit of a target location corresponding to a failure mode leading to its structural and functional damage due to inundation and immersion, wave power, scouring, collision of drifting articles, and movement of seabed sand caused by a tsunami will be assessed as realistic capacity. In general, a probability distribution with an upper and a lower limit will be assumed for a functional damage mode due to inundation and immersion caused by a tsunami, whereas a logarithmic normal distribution will be assumed for a structural and functional damage mode due to wave power, scouring, collision of drifting articles, and movement of seabed sand caused by a tsunami.

There aren't enough experimental capacity data to show the quantitative values of logarithmic standard deviation for the different failure modes. But functional failure of electric equipment seems to be cliff-edge capacity and, as an example of current study, JAEE(2015) shows $\beta_{\mathrm{c}}=0.10 \sim 0.30$ for sea wall or breakwater structural failure capacity against wave power.

\section{Uncertainty of response of SSC}

Inundation height, etc., at a damage-expected location corresponding to a failure mode, which leads to structural and functional damage due to inundation and immersion, wave power, scouring, collision of drifting articles, and movement of seabed sand caused by a tsunami, will be assessed as probabilistic quantities. In general, a logarithmic normal distribution will be assumed.

Considering the external and internal barriers such as sea wall and water-tight door, general uncertainty concept of realistic capacity and response of each failure mode of SSCs are shown in Figure 4 to Figure 6 corresponding to assumed three levels of tsunami height at control point. 




Figure 4: Uncertainty of capacity and response; (1) low level of tsunami

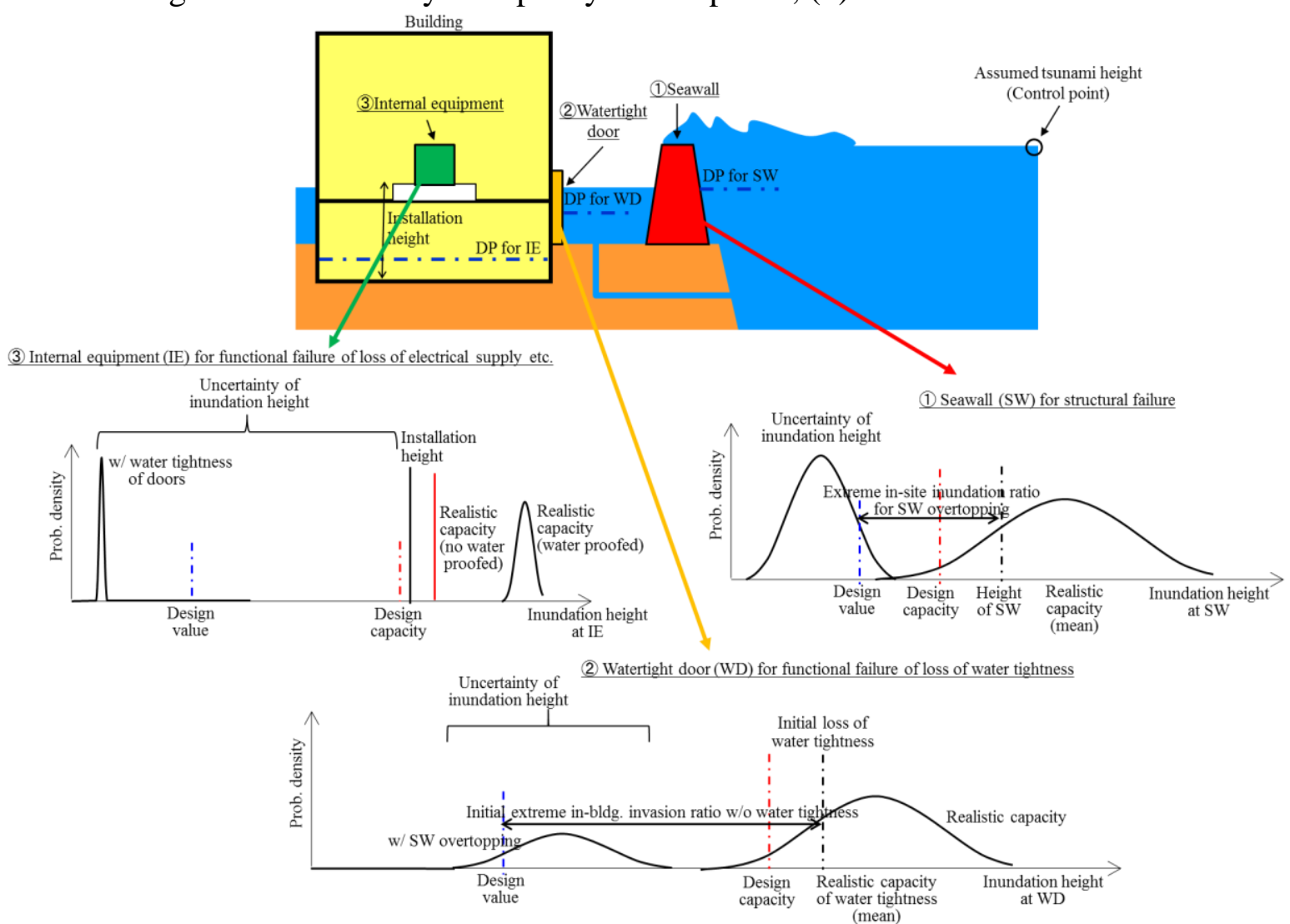

Figure 5: Uncertainty of capacity and response; (21) medium level of tsunami 


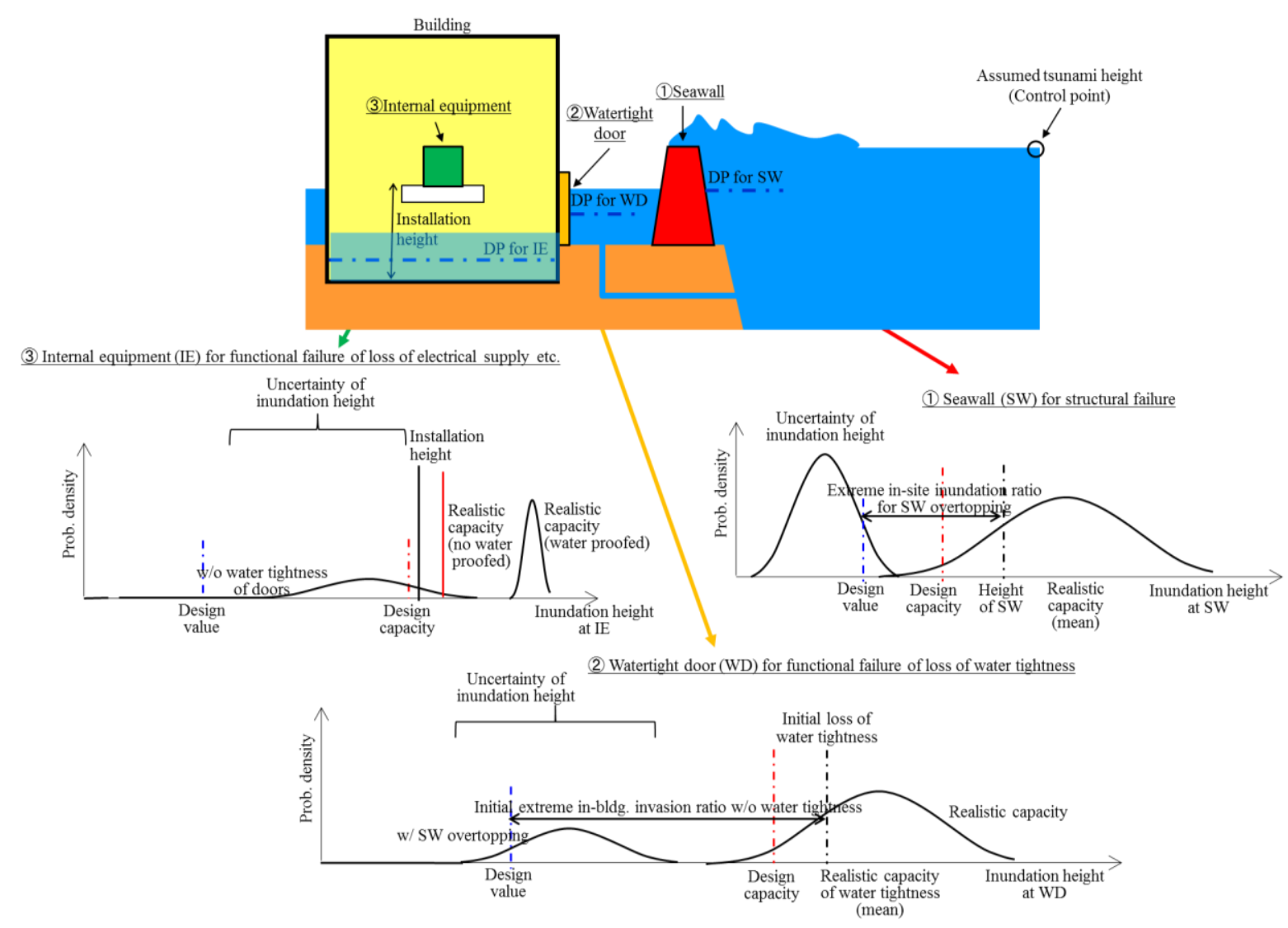

Figure 6: Uncertainty of capacity and response; (3) high level of tsunami

There aren't enough experimental and analytical response data to show the quantitative values of logarithmic standard deviation for the different failure modes. Although it varies from the results of tsunami propagation and inundation calculations, based on the results of current study, $\beta_{\mathrm{r}}$ for inundation height is about 0.10 referred to analytical results by Sugino et al (2008) and $\beta_{\mathrm{r}}$ for flow velocity is about 0.20 referred to observed tsunami records in 2011 off the Pacific coast of Tohoku Earthquake. Also $\beta_{\mathrm{u}}$ for inundation height is $0.25 \sim 0.50$ referred to the difference between observed tsunami records and tsunami inundation analyses by AESJ (2012). Regarding wave power pressure due to tsunami, $\beta_{\mathrm{c}}$ is about 0.50 referred to experimental results by AESJ (2012).

\section{Fragility evaluation of SSC}

Following the generic equations (4) through (11b), the fragility curves of buildings and components for various kinds of failure modes due to tsunami will be basically calculated. Typical examples of response and capacity distributions for various kinds of failure modes to calculate fragility curves of SSCs are shown in Figure 7.

AESJ (2012) shows an example of approach to evaluate fragility curves of SSCs for structural failure caused by wave power and collision of drifting due to tsunami. Sugino et al (2008) also conducted various tsunami run-up analyses from the wave source and evaluated the fragility curve for the functional failure mode due to inundation and immersion of SSC in a reactor building. Figure 8 (left) shows the relationship between the inundation height at a point $200 \mathrm{~m}$ inland from the shoreline, and the maximum tsunami water level (maximum wave height) at the shoreline by plotting individual data. In this diagram, the limit water level 
Structural damage mode due to wave power, scouring, collision of drifting

(articles, and movement of seabed sand

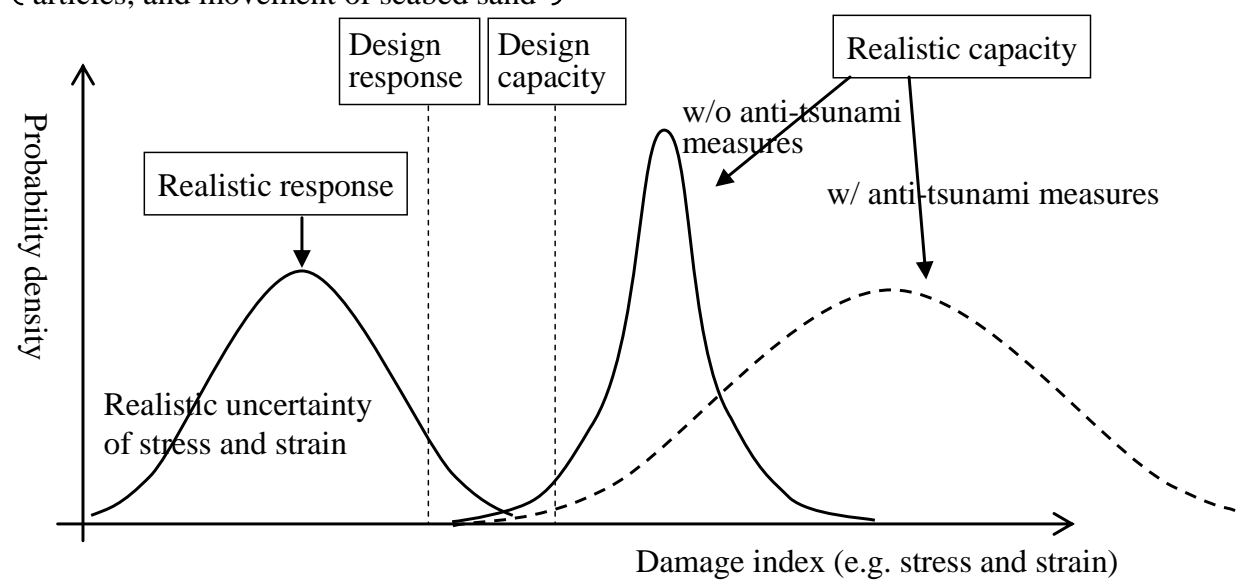

$\left[\begin{array}{l}\text { Functional damage mode } \\ \text { due to immersion }\end{array}\right]$

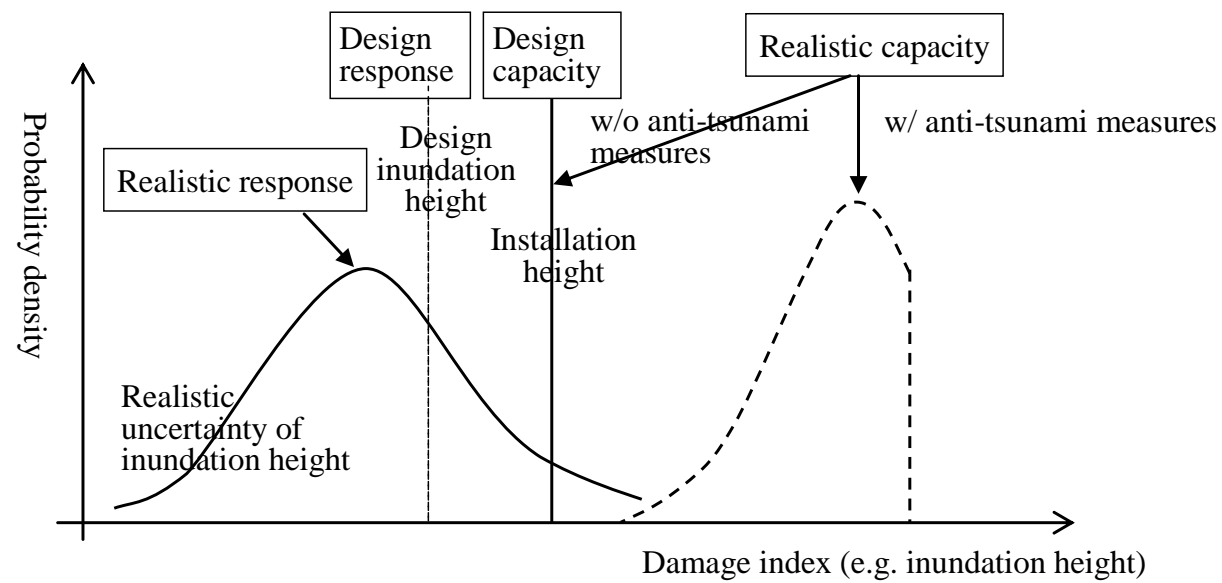

$\left[\begin{array}{l}\text { Functional damage mode } \\ \text { due to inundation }\end{array}\right]$

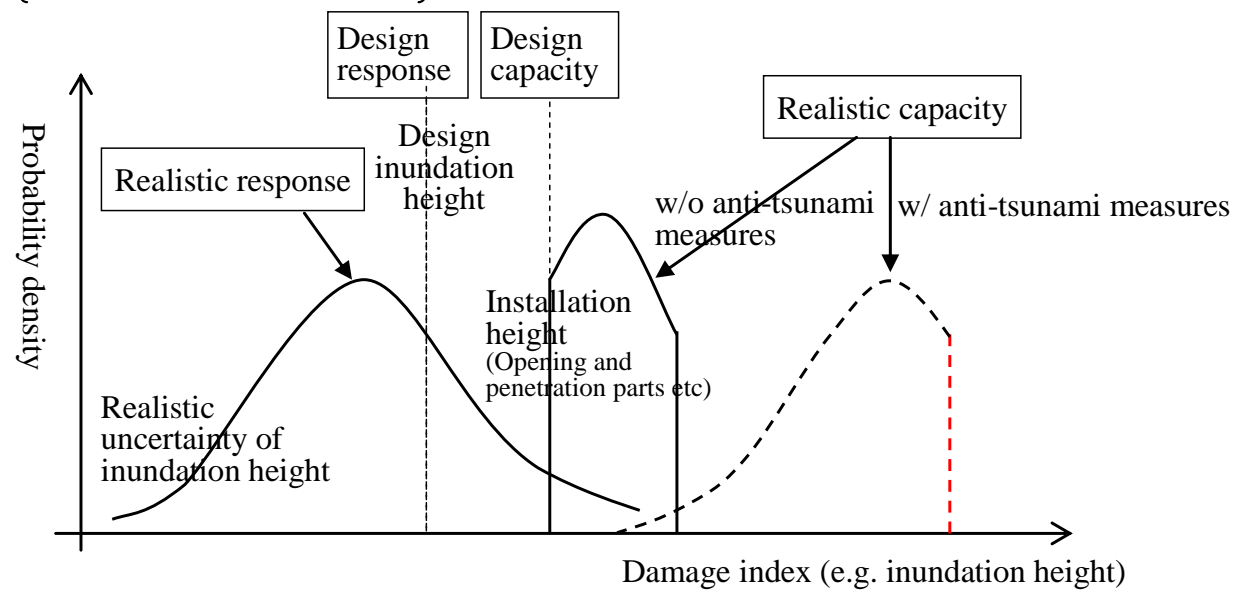

Figure 7 Typical examples of response and capacity distributions for various kinds of failure modes [Mihara et al (2012)] 

$\mathrm{R} / \mathrm{B}$ assumed at the $200 \mathrm{~m}$
from shoreline

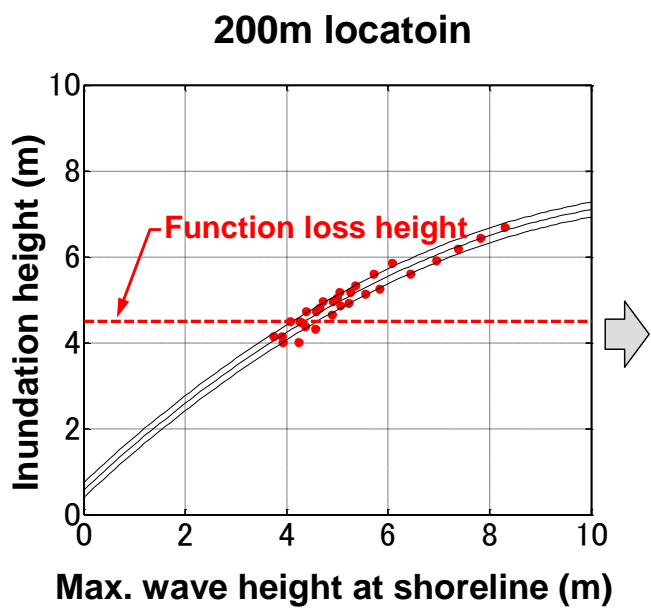

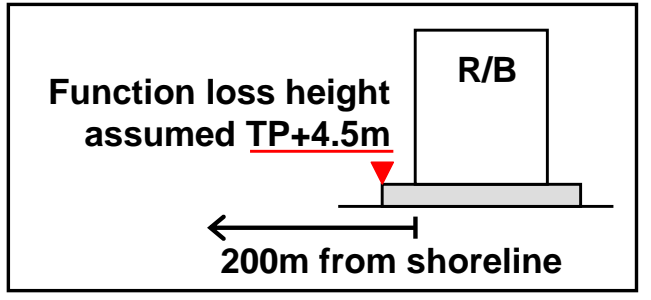



Figure 8: Inundation height at 200m inland from the shoreline (left) and the relationship between maximum wave height (maximum tsunami water level) and fragility curve assessment (right) [Sugino et al (2008)]

of functional damage (functional loss height), TP+4.5m is indicated, on the assumption that the assessment target reactor building is located at this point. Fragility curves will be assessed as follows using the data on Figure 8 (left). First, approximation curves will be calculated from the plotted results of the run-up analysis by using the method of least squares. Then the dispersion of the differences between the values of the approximation curves and the inundation heights of individual plotted points will be assessed. Subsequently, probability distribution with the values of approximation curve regarded as medians will be obtained for each of the maximum tsunami water level (maximum wave height) at the shoreline. Finally, the probability on the condition that the limit water level of functional damage (functional loss height) will be exceeded in this distribution will be assessed, thereby, the fragility curve will be obtained as shown in Figure 8 (right).

\section{FURTHER DISCUSSION}

Nie et al (2013) undertook comparison of US seismic fragility data with JNES test data for motor operated valves, fans and tanks. The fragility capacities, either obtained directly from full-scale shaking table tests or estimated from the JNES test-based methods, were in general much higher than or confirmed those used in the U.S. SPRA practice. The JNES fragility test program uncovered failure modes, such as, malfunction of the clutch lever on certain valves, wearing-out of labyrinth seals on fans, secondary buckling for tall tanks, and shear buckling for short tanks, that have not been considered explicitly in U.S. PRA practice. Caution must be exercised in using the JNES test results, including the test-based evaluation methods, to any specific case of fragility analysis. The generic values of $F_{(.), m}$ and $\beta_{(.) *}$ and other parameters summarized in this paper are from published literature and mostly based on USA fragility data. These values should be used in any non-USA plant after careful examination on applicability. 
Bayesian updating could be a useful tool to use generic data published in literature to any specific plant of different genre. Tadinada and Gupta (2013) propose a methodology to incorporate newly available fragility data to update the existing seismic fragility estimates as long as the data can be organized into a given format. The fragility estimates based on the conventional log-normal model EPRI (1994) using generic data is considered as "prior" information. The "posterior" fragility curve is obtained by updating the prior fragility with new information applying Bayesian updating techniques. The new information may be from plant specific information or information obtained from variety of sources like experiments, safety analysis, structural health monitoring, etc.

AESJ (2011) pointed out that the currently available flood including tsunami fragility evaluation methods for the following four items contain significant epistemic uncertainty, more accurate methods are expected to be developed.

1. To evaluate uncertainly for cumulative failure mode affecting related SSCs due to inundation and immersion, with consideration given to the temporal cumulative effects of multiple tsunami events

2. To evaluate uncertainly for structural failure mode affecting the stability of buildings and structures due to scouring caused by tsunami events

3. To evaluate uncertainly for structural and functional failure mode affecting related $\mathrm{f}$ SSCs due to collision of drifting debris caused by tsunami events

4. To evaluate uncertainly for structural, functional and cumulative failure mode when multiple failure modes are correlated.

\section{EXTERNAL EVENT PSA FOR MULTI-UNIT SITES}

Recent events have highlighted the need for evaluating risks caused by external natural events from multi reactor units located at a site. There are a number of sites in the world with three or more operating reactor units. More details regarding the multi-unit external hazards PSA can be obtained from the IAEA report [IAEA, 2015a]. The overall EE- PSA methodology of singe unit for natural hazards like earthquakes, high wind and flood could be modified for multi-unit sites.

As a best practice, the development of a multi-unit PSA model for internal event fully accounting for the shared systems and components between the units is recommended as a prerequisite for a multi-unit wind PSA. The PSA system analyst will make suitable modifications to this multi-unit PSA model for the wind hazard. Certain initiating events, depending on the plant design, could affect multiple units; an example could be loss of offsite power since the switchyard is generally shared between the units. Other examples are loss of service water and loss of instrument air. In one PWR plant, the condensate storage tanks (CST) are cross-tied and shared between two units. The levels are maintained to accommodate an accident on one unit and hot shutdown on the other unit. However, the CSTs will not last the mission time and service water is required to meet the mission time for auxiliary feed-water. The analyst should properly model the initiating events, shared SSCs and the availability of different SSCs under multi-unit initiating events. The accident sequence analysis and quantification will proceed using the same methodology as for single reactor unit. Modelling of human reliability and operator recovery actions for multi-unit accidents requires additional considerations of duration of the wind hazard, damaged state of SSCs in different units, access to certain areas requiring operator action, and availability of 
emergency response such as firefighting. The analyst should examine various "what if" scenarios and assign subjective probabilities to carry out the quantification.

The key point of seismic PSA of a multiunit site is the correlation of SSC seismic response between different units The correlation arise out of geotechnical characteristics of site, soil structure interaction, seismic ground motion parameters like response spectrum, design (civil engineering buildings/structures, equipment, piping, service system, etc.). This results in fragility correlation, for which adequate data is not available. Hakata (2006) developed a Fault Tree linked Monte Carlo approach for Seismic Level-1 PSA models for analyzing simultaneous failure probability of multiple nuclear power plants in a site. Amongst other areas, realistic data for inter-plant and across plant response and fragility correlation coefficients of SSC for multiples units needs further development.

Wind hazard discussed in IAEA SRS-8.3 is generally applicable to the plant site. Typically, the winds arising from straight winds (thunderstorms and extra-tropical cyclones) and hurricanes cover a large region and all buildings and outdoor equipment of the multi-units at the site experience the same wind loading. The same could be said about the larger tornadoes of interest to the PSA. The wind pressure fragilities of SSCs at multi-units are also derived from the wind loading experienced by the SSCs. As such identical SSCs of multi-units at the site have the same fragilities. The current state of the art procedure for tornado/hurricane missile damage fragility evaluation is to perform simulation tracking the potential objects that could become missiles for different tornadoes and hurricanes passing through the site. This procedure is suitable for tracking the simultaneous missile hits or damage to SSCs of multiunits identified by the PSA systems analyst. Currently, no published studies are available to develop approximate conditional probabilities of the second target being hit or damaged (by one of more separate missiles) given the missile hit on the first target. It is a function of the distance between the targets and the structural barrier enclosing the targets.

Similar to seismic PSA, one of the key points of flood PSA of a multiunit site is the correlation of response values at SSC points between different units such as inundation height/depth, flow velocity and water pressure. The correlation arises out of geotechnical characteristics of site and geometry characteristic of buildings/structures calculated from tsunami propagation and inundation analyses. In addition to that, barriers' fragility such as protective walls, water-tight doors and sealing countermeasures has severe impacts to the correlation of response values between different units. It means that, comparing to earthquake and wind one, the correlation of the flood fragility is highly path-dependent and thus flood hazard is influenced by barriers' fragility. The key additional considerations on a multiunit site include the flood effects such as debris/debris flow and morphological changes related to deposition. Especially, multiple physical impacts of debris due to flood cause significant damage to SSCs of multi-units and also oil or chemical spill due to flood flow potentially produce other external risks such as fire/explosion leading to multiunit failures.

EE-PSA for multi- units provides estimates of Site CDF (SCDF) and SLERF (Site Large Early Release Frequency) along with the significant risk contributors. The uncertainty bounds on these SCDF are also developed. These outputs should help in any upgrading decisions if the absolute values of SCDF and SLERF from wind induced events exceed the acceptable limits.

It may be noted that EE- PSA of multi-reactor unit sites for natural hazards, if any, has not been reported in the open literature. 


\section{SUMMARY AND CONCLUSIONS}

1. The paper has made a brief survey of literature and summarizes the approaches determining the parameters (i.e. $D_{m}, \beta_{R}, \beta_{U}$ or $\beta_{c}$ ) to derive fragility of SSC of an NPP for seismic, high wind and flood hazards. Generic approach for fragility calculation and capacity assessment of component for seismic, high wind and flood hazards are presented. The methodology of fragility parameter calculation for these three hazards is discussed in detailed summarizing the information available in literature. Derivation of system fragility is also briefly discussed.

2. There are broadly two approaches for seismic fragility calculation of NPP component -1 ) Fragility method or separation of variable approach, and 2) Hybrid method or CDFM based approach. For fragility analysis method, a generic formulation is used to derive factor of safety $F$ in terms three other scaling factors; $F_{1}$-strength factor, $F_{2}$-factor to correspond conservatism in capacity assessment, $F_{3}$-factor to represent conservatism in determining demand. The paper summarizes alternative approaches to derive the median values of these scaling factors and associated uncertainties $\left(\beta_{R}, \beta_{U}\right.$ or $\left.\beta_{c}\right)$ for SSC qualified by analysis, test and experience based method. In case of hybrid method, approach for deriving family of fragility curves from the CDFM capacity and $\beta_{C}$ value presumed on the basis of experience is presented along with recommended values of fragility parameters.

3. Wind PSA has become important in recent years. Existing nuclear power plants in many countries do not have tornado or hurricane (typhoon) considerations in their design. They have typically adopted wind loading provisions from building standards. Site-specific wind hazard analysis accounting for different applicable sources (i.e., tornado, hurricane and straight winds) should be done to develop input to wind PSA.

4. Bounding analysis procedures need to be developed along with specific requirements on plant design review and walk down. Currently, ASME/ANS PRA Standard Part 7 is developing these requirements for application to US nuclear power plants.

5. Plant walk down and missile surveys require experienced analysts and are very labor intensive; the results and insights from past studies should be used to develop simplified

6. Approaches for focused walk down and missile surveys.

7. Flood fragility generally shows more cliff-edge shape without any special barriers (e.g. protective walls, water-tight doors and sealing countermeasures). It means that flood fragility is highly path-dependent and thus flood hazard is influenced by barriers' fragility.

8. Tsunami fragility evaluation needs not only tsunami height but also various kinds of parameters which will be converted into load effects such as hydrodynamic force, morphological change and collision of drifting debris. Correlation between them from tsunami source to each SSC points is also necessary.

9. AESJ (2011) specifies the technical requirements for performing the tsunami PSA. Based on the technical background, AESJ (2012) also shows the field investigation of the actual tsunami disaster and application examples for tsunami fragility. Regarding combination 
fragility between earthquake and tsunami, Mihara et al (2014) categorized the mixed failure modes and specified the fragility procedures for tsunami barriers.

10. Generic fragility data available in literature should be used in fragility analysis of any particular plant after careful examination of its applicability specific to that plant.

11. Bayesian statistical framework may be applied to update the fragility estimate of a specific plant based on generic data using plant specific information and new information.

\section{ACKNOWLEDGEMENT}

Authors acknowledge the help and suggestions of Mr. A. S. Pisharady, Atomic Energy Regulatory Board, in preparation the portion on seismic fragility.

\section{REFERENCES}

American Society of Civil Engineers (ASCE). (2013) "Minimum design loads for buildings and other buildings structures", ASCE/SEI Standard 7-10, 2013.

Atomic Energy Regulatory Board (AERB). (2001). Design of concrete structures important to safety of nuclear facilities, AERB/SS/CSE-1. Mumbai, India

Atomic Energy Society of Japan (AESJ). (2011) "Implementation standard concerning the tsunami probabilistic risk assessment of nuclear power plants", A Standard of the Atomic Energy Society of Japan, AESJ-SC-RK004E :2011.

Atomic Energy Society of Japan (AESJ). (2012). "Case studies of implementation standard concerning the tsunami probabilistic risk assessment of nuclear power plants", AESJ-SC-TR006 : 2012.

American Soc. Mechanical Engineers and American Nuclear Soc. (ASME/ANS). (2011). "Standard for level 1/large early release frequency probabilistic risk assessment for nuclear power plant applications" ASME/ANS RA-Sb-2013

ARA (2014). "High wind hazard and fragility analysis of MNS" ARA-002064.

Bozoki, G. E., Fitzpatrick, R. G., Bohn, M. P., Sabek, M. G., Ravindra, M. K., Johnson, J. J. (1994). Review of Diablo Canyon Probabilistic Risk Assessment, NUREG - 5726, United States Nuclear Regulatory Commission, Washington D.C., USA.

Budnitz, R. J., Amico, P. J., Cornell, C. A., Hall, W. J., Kennedy, R. P., Reed, J. W., Shinozuka, M. (1984). An approach to the qualification of seismic margins in nuclear power plants, NUREG/CR-4334, USNRC, Washington D. C., USA.

Cover, L. E., Bohn, M. P., Campbell, D. A. and Wesley, D. A. (1983). Handbook of nuclear power plant seismic fragilities, NUREG/CR-3558, LLNL, East avenue, Livermore, California, USA.

Chang, C.C., Chou, C. C., Shen, Y. H. and Huang, Y. N. (2013), "Development of Response Based Fragility Curves for Seismic Probabilistic Risk Assessment of Nuclear Power Plants", Div. VII, Proc. $22^{\text {nd }}$ Int. Conf. on Structural Mechanics in Reactor Technology (SMiRT 22), San Francisco, USA.

Department of Energy (DOE). (2002). Natural Phenomena Hazards Design and Evaluation Criteria for Department of Energy Facilities, DOE STD 1020 - 2002. United States Department of Energy, Washington D.C., USA

Electric Power Research Institute (EPRI) (2012) Seismic evaluation guidance -screening, prioritization and implementation details (SPID) for the resolution of Fukushima 
Near-Term Task Force recommendation 2.1: seismic, Report 1025287, California, USA.

Electric Power Research Institute (EPRI) (2009) Seismic fragility applications guide, Report 1019200, California, USA.

Electric Power Research Institute. (EPRI). (2002). Seismic fragility application guide, TR1002988. California, USA.

Electric Power Research Institute (EPRI). (1994). Methodology for deriving seismic fragilities, TR-103959. California, USA.

Electric Power Research Institute (EPRI) (1991). A methodology for assessment of nuclear power plant seismic margin, EPRI NP-6041-SL, Revision 1, Electric Power Research Institute, Palo Alto, California,

Ellingwood, B. (1994). Validation of seismic probabilistic risk assessments of nuclear power plants, NUREG/GR-008, USNRC, Washington D. C., USA.

Hakata, T. (2006). Seismic PSA method for multiple nuclear power plants in a site, Reliability Engineering and System Safety 92, 883-894, UK.

Institute of Electrical and Electronics Engineers (IEEE). 1997. Recommended practices for seismic design of substations, Standard 693-1997. New York, USA.

International Atomic Energy Agency (IAEA) (2015). Assessment of hydrological (excluding tsunami) and high wind hazards, Safety Report Series SR 8.3 (Under publication), Vienna, Austria.

International Atomic Energy Agency (IAEA, 2015a). Technical approach for multi-unit site probabilistic safety assessment, Safety Report Series SR 8.5, (under publication), Vienna, Austria.

International Atomic Energy Agency (IAEA). (2010). Seismic hazards in site evaluation for nuclear installations, IAEA-SSG-9. Vienna, Austria.

International Atomic Energy Agency. (IAEA). (2003). Seismic Evaluation of Existing Nuclear Power Plants, Safety Reports Series No. 28. Vienna, Austria.

Japan Association for Earthquake Engineering. (JAEE). (2015). Tsunami resistant engineering for nuclear safety -toward integrated framework for earthquake-tsunami protection-, Japan.

Kaasalainen, S., L.A.Twisdale,. A.Suady, P.J. Vickery and M. Gerchikov : "Practical approach to implement level-1 high wind PRA" Transactions of SMiRT-22, Division VIII, San Francisco, CA, USA.

Kennedy R P. and Ravindra M K. (1984). "Seismic fragilities for nuclear power plant risk studies". Nuclear Engineering and Design, 79, pp 47-68, UK.

Kennedy, R. P., Cornell, C. A., Campbell, R. D., Kaplan, S. and Perla, H. F. (1980). "Probabilistic seismic safety study of an existing nuclear power plant". Nuclear Engineering and Design, UK, 59, pp 315-338.

Kennedy, R. P., Campbell, R. D., Hardy, G. and Banon, H. (1982). Subsystem fragility seismic safety margins research program (phase I), NUREG CR-2405. Lawrence Livermore National Laboratory, Livermore, California, USA.

Kramer, L. S. (2007). Geotechnical earthquake engineering. Prentice Hall International, Noida, India.

Mihara, Y., Yamaguchi, A., Kirimoto and Y., Matsuyama, M. (2012). "Tsunami PRA standard development by Atomic Energy Society Japan (AESJ) (3) tsunami fragility analysis", PSAM11, 2012

Mihara, Y., Yamaguchi, A., Nakamura, S., Tsutsumi, Y. and Iijima, T. (2014). "Revision of the AESJ standard for seismic probabilistic risk assessment (3) fragility evaluation”, PSAM12, 2014 
Nie, J. R., Hofmayer, C. H. and Stovall, S. P. (2013). "Comparison of US seismic fragility data with JNES test data for motor operated valves, fans and tanks", Div. VII, Proc. $22^{\text {nd }}$ Int. Conf. on Structural Mechanics in Reactor Technology (SMiRT 22), San Francisco, USA.

Park, Y. J., Hofmayer, C.H. and Chokshi, N.C. (1998). "Survey of seismic fragilities used in PRA studies of nuclear power plants", Reliability Engineering and System Safety, 62, pp 185-195.

Pishrady, A. S. and Basu, P. C. (2010). "Methods to derive seismic fragility of NPP components: a summary”, Nuclear Engineering and Design, UK, 240 (2010) 38783887.

Prassinos, P. G., Ravindra, M. K. and Savy, J. B. (1986). Recommendations to the nuclear regulatory commission ontTrial guidelines for seismic margin reviews of nuclear power plants, NUREG/CR - 448. Lawrence Livermore Laboratory, California, USA.

Ravindra, M.K. Z.M. Li, P. Guymer, D. Gaynor and A. DiUglio, "High wind IPEEE of Indian Point unit 2", Transactions of 14th SMIRT Conference, August 1997, Lyon, France

Reed, J.W. and W.L. Ferrell, "Extreme wind analysis for the Point Beach nuclear power plant," Appendix G in "Shutdown Decay Heat Removal Analysis of a Westinghouse 2Loop PWR", Report NUREG/CR-4458, Sandia National Laboratories, 1987

Salmon, M. W. and Kennedy, R. P. (1994). Meeting Performance Goals by the Use of Experience Data, UCRL CR-120813. LLNL and DOE, USA.

Sugino, H., Iwabuchi, Y., Nishio, M., Tsutsumi, H., Sakagami, H. and Ebisawa, K. (2008), "Development of probabilistic methodology for evaluating tsunami risk on nuclear power plants", The 14th World Conference on Earthquake Engineering.

Tadinada, S. K. and Gupta, A. (2013). "Bayesian updating of seismic fragility of structures using time history simulator", Div. VII, Proc. $22^{\text {nd }}$ Int. Conf. on Structural Mechanics in Reactor Technology (SMiRT 22), San Francisco, USA.

Twisdale, L.A. (1988) "Probability of facility damage from extreme wind effects," Journal of the Structural Division, Vol 114, No. ST10, pp. 2190-2209, American Society of Civil Engineers (Oct 1988).

Twisdale, L.A. and P. J. Vickery, "Extreme wind risk assessment," Probabilistic Structural Mechanics Handbook - Theory and Industrial Applications, Chapter 20, C. Sundararajan, Editor, Chapman and Hall, New York (1995).

United States Nuclear Regulatory Commission (USNRC) (1983). PRA procedures guide, a guide to the performance of probabilistic risk assessments for NPP, NUREG CR2300, Vol.2. Washington D. C., USA. 